Article

\title{
Practical Application of Nanotechnology Solutions in Pavement Engineering: Construction Practices Successfully Implemented on Roads (Highways to Local Access Roads) Using Marginal Granular Materials Stabilised with New-Age (Nano) Modified Emulsions (NME)
}

\author{
Gerrit J. Jordaan ${ }^{1,2, * \mathbb{D}}$ and Wynand J. vdM. Steyn ${ }^{3}(\mathbb{D}$ \\ Department of Civil Engineering, University of Pretoria, Pretoria 0002, South Africa \\ 2 Jordaan Professional Services (Pty) Ltd., Pretoria 0062, South Africa \\ 3 School of Engineering and Department of Civil Engineering, University of Pretoria, Pretoria 0002, \\ South Africa; Wynand.steyn@up.ac.za \\ * Correspondence: jordaangj@tshepega.co.za; Tel.: +27-(0)-824164945
}

check for updates

Citation: Jordaan, G.J.; Steyn, W.J.vdM. Practical Application of Nanotechnology Solutions in Pavement Engineering: Construction Practices Successfully Implemented on Roads (Highways to Local Access Roads) Using Marginal Granular Materials Stabilised with New-Age (Nano) Modified Emulsions (NME). Appl. Sci. 2022, 12, 1332. https:// doi.org/10.3390/app12031332

Academic Editors: Luís Picado Santos and João Crucho

Received: 22 December 2021

Accepted: 20 January 2022

Published: 26 January 2022

Publisher's Note: MDPI stays neutral with regard to jurisdictional claims in published maps and institutional affiliations.

Copyright: (C) 2022 by the authors. Licensee MDPI, Basel, Switzerland. This article is an open access article distributed under the terms and conditions of the Creative Commons Attribution (CC BY) license (https:// creativecommons.org/licenses/by/ $4.0 /$ )
Featured Application: The general use of New-age (Nano) Modified Emulsions (NME) is applicable for the construction of high-order multi-lane highways to lower-order access roads in villages/townships. These nanotechnology solutions are suitable for use with construction equipment ranging from the most sophisticated to elementary, including labour-enhanced construction methods. NME enhancement/stabilisation of materials for use in roads enable the use of marginal materials in all categories of roads. The general acceptance of these new disruptive technologies will be driven by the ease of use, time, cost implications, and robustness of the technology during construction in practice, with an associated reduction in risks and costs.

Abstract: The introduction of any new disruptive technology in a traditionally well-established industry, such as the road construction industry, is usually associated with considerable resistance. This is especially relevant when the new technology is based on the use of granular materials traditionally considered to be of an unacceptable quality in combination with relatively new concepts such as New-age (Nano) Modified Emulsions (NME). In such cases, the fact that the material design methods are based on fundamental scientific principles and have been proven in both laboratories and through Accelerated Pavement Testing (APT) may be of little influence. However, the general acceptance of new disruptive technologies, e.g., telecommunications and Information Technologies (IT), have been based on the considerable advantages it presented. The same principles are applicable to the general acceptance and use of the NME stabilisation/enhancement of materials in the road construction industry. This article is aimed at the practical cost-effective demonstration of the general application of the use of nanos-silane-modified emulsions in the construction of the highest order roads, i.e., inter-city multi-lane highways, lower-order roads (including Low-Volume Roads (LVR)), and even local accesses to farms and in villages/townships. The implementation of NME technologies is directly associated with ease of use, time, and cost savings, and with the addressing and reduction of risks applicable to the use thereof.

Keywords: construction practices implemented in nanotechnology stabilisation; nano-modified emulsion (NME) stabilisation of granular materials; central plant mixing of NME granular materials; in situ recycling using nanotechnology emulsions; rehabilitation using nano-modified emulsion technologies; conventional plant mixing of granular materials; usage of marginal granular materials; cost-effective usage of granular materials in road construction; implementing nanotechnologies in practice; nanotechnology construction in roads 


\section{Introduction}

The introduction of any new disruptive technology [1] in a traditionally well-established industry, such as the road construction industry, is usually associated with considerable resistance. This is especially relevant when the new technology is based on:

- The use of granular materials traditionally considered to be of marginal or even unacceptable quality [2];

- Relatively new concepts in pavement engineering such as New-age (Nano) Modified Emulsions (NME) [3];

- Test requirements such as XRD scans [4] (relatively old concepts in fields such as geology and mining) to analyse naturally available granular materials [5];

- Scientific material design methods including the basic generic fingerprinting of materials mineralogy and scientific principles involved in the identification of materialcompatible nano-modified stabilising agents [6,7]; and

- Pavement layer bearing capacity tests, which, in a traditional sense, may be foreign to the road construction industry, i.e., Unconfined Compressive Strengths (UCS) [8] and Indirect Tensile Strengths (ITS) [9].

Although most of these concepts have been in use for many decades, if not more than a century, especially in the built environment $[10,11]$, the traditional road construction industry is notoriously conservative and slow to adapt. In such an environment, the fact that the stabilised granular material design method is based on fundamental scientific principles $[6,12,13]$, has been evaluated and proven in national research and university laboratories [14-16], and has been evaluated in practice through Accelerated Pavement Testing (APT) [17-19] and implemented on several roads in southern Africa [7,20] may have little effect to address the scepticism and reservations in the road construction industry.

In order to be of benefit and to assist in addressing the considerable backlog in transportation infrastructure in (especially) the developing regions of the world, the practical aspects associated with new technologies must be proven to such a degree that all doubts are sufficiently addressed in order to overcome a natural resistance to change. A good transportation infrastructure network forms the backbone and is a pre-requisite to the economic development of any country. Hence, any potential considerable savings in the unit costs for the provision and maintenance of road infrastructure (without compromising quality and durability) need to be adopted without delay. This can be accomplished through pre-empting any construction-related concerns and addressing potential problems as well as risks for general acceptance to be achieved.

Accelerated acceptance of the introduction of new disruptive technologies, such as in the telecommunications industry (cell/mobile phones) and in Information Technologies (IT; computer technologies), has been based on the considerable advantages these technologies present to the general population. The same principles are applicable to the general acceptance and successful use of the NME stabilisation/enhancement of granular materials in the road construction industry. Proven benefits and risk reductions to the road construction industry will lead to the adoption of nanotechnology solutions despite traditional resistance to change. The objectives of this article are to demonstrate the ease of use and the practical advantages of the implementation of the NME stabilisation of naturally available granular materials. The applicability of these technologies is demonstrated through examples of the actual implantation of NME-stabilised granular materials in the layer-works of roads. These roads vary from the highest-order roads (i.e., inter-city multi-lane highways) to lower-order access roads (i.e., Low-Volume Roads (LVR)) and even to local accesses to farms as well as in villages/townships. It is emphasised that this is not a literature study of available construction practices but represents the actual use of NME stabilising agents using granular materials that would traditionally be rejected for use in the pavement structural layers.

No technology is without risks. However, a rigorous process of risk assessment, the development of a scientifically based material design method $[6,12,13]$, laboratory 
evaluations [14-16], and full-scale APT loading assessments [17-19] allowed for design risks to be minimised.

It is shown that normal, commonly used construction methods can be used with ease for the construction of pavement layers in roads using central mixing plants, recyclers, conventional equipment, or labour-enhanced construction methods. Not only can any available construction method be effectively used but in many cases, the NME stabilising agent shows considerable advantages over and above the use of materials traditionally used. These advantages are highlighted towards the end of the article though practical experience gained over the last decade with associated savings.

\section{Construction Industry Acceptance of New Technologies}

The introduction and general acceptance of any new technology in an established industry are a function of a number of factors, including:

Primary construction-related interest factors influencing new technology introduction include;

- Influence on profitability;

- Required equipment and cost thereof;

- $\quad$ Ease of construction;

- Production rates to be achieved;

- Delays caused by slow drying/setting and curing of materials;

- Risk associated with implementation;

- Actions required to reduce risks;

- New skill-set requirements for practical implementation;

- Industry resistance to change as a function of comfort with design approaches and vested interests; and

- $\quad$ Perceived threats to established monopolies.

Additionally, important aspects, with major implications on the construction phase of any project, that must be addressed during the design phase $[8,13]$ and through legislation include:

- Toxicology (normally addressed through legal requirements and materials approval);

- Environmental factors (normally addressed by legislation and materials approval); and

- Addressing the unknown, i.e., the fear-factor, by demonstrating safety, opportunities, and benefits, and by addressing scepticism among traditionalists.

Most of these primary factors and the additional factors have already been discussed in detail in the various publications referenced. The practical construction issues, e.g., the applicability of equipment, required modifications to equipment, use of existing equipment, damage to equipment, capital requirement for the acquisition of new equipment, and similar concerns, will be addressed throughout this article.

The versatility and ability of the anionic NME stabilisation/enhancement of granular materials to address needs at all levels of the road construction industry are of prime importance. It enables the fiscus and authorities to provide more infrastructure at considerably reduced costs without compromising the engineering quality. As demonstrated in this article, the implementation of NME technologies will reduce the risks to contractors (ease of implementation/operations, generating of opportunities for entering the market space, and generation of more projects with the same available funds) and create opportunities to maintain or increase profitability.

\section{Defining Marginal Materials}

The use of marginal materials in road pavement design and construction is usually associated with Low-volume Roads (LVR). This general perception among pavement engineers in terms of the optimum utilisation of granular materials will require a total mind-shift in traditional perceptions with the introduction of applicable, proven nanotechnologies. With the enhancement, protection, and stabilisation of granular materials using 
proven nanotechnology applications (organofunctional silane technologies), the traditional perception of marginal or unsuitable granular materials for use in specific pavement layers as a function of design criteria is far from accurate. It is by far easier to adjust and enhance the material properties of a relatively good-quality granular material (just not meeting the standards of freshly crushed stone) compared to that of the enhancement/improvement of a very poor-quality material containing high percentages of secondary minerals. The definition of "marginal" materials and the use thereof in various road categories is discussed using the basic, easily comparable, relative qualities of the South African granular material classification system [21] for road construction, as summarised in Figure 1. This material classification system is used as a basis due to the simplistic nature of reference ranging from a very good freshly crushed stone (G1) to a very poor material consisting mostly of clay-like materials (G10). For a full understanding of the South African granular material classification system, as well as a scientific basis of the nanotechnology solutions, the various references should be studied [21-23].

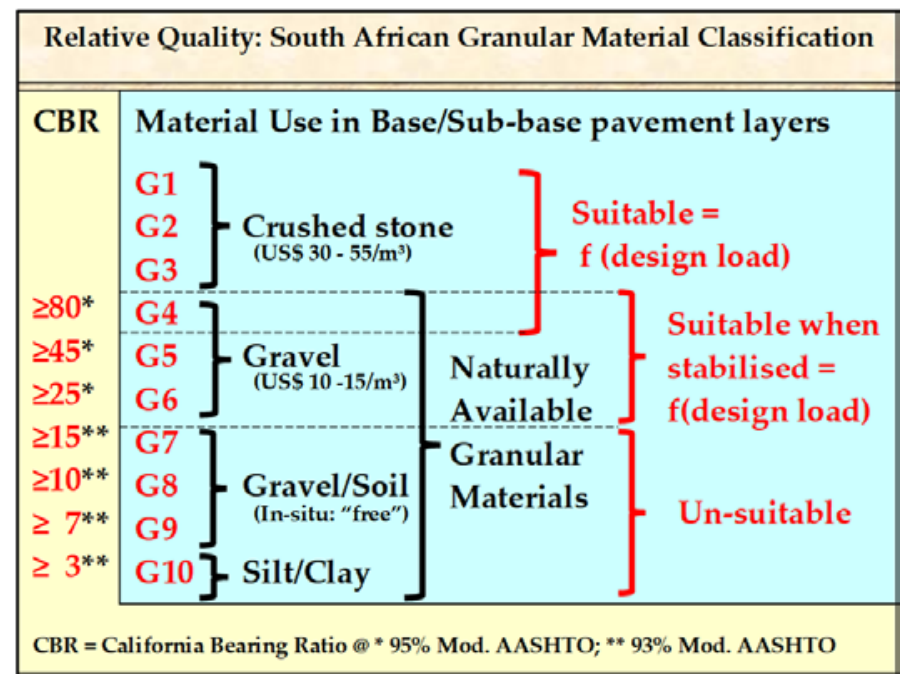

Figure 1. Summary of the comparative relative qualities of granular materials as defined using the South African road building material classification system [21-23] (for definition of Mod AASHTO, refer to [24,25]). Typical material costs shown are based on South African experience (2021, excluding haulage costs) and these costs may vary considerably.

The traditional material classification system presented in Figure 1 [21-23] and the use thereof in practice is, of course, a function of the design traffic loading, usually expressed in terms of the equivalent number of dual-wheel $80 \mathrm{kN}$ single axle loads (E80s) calculated over the design period [22,26]. The design E80s are closely associated with the category of the road, the expected Level Of Service (LOS), and the number of vehicles (capacity) on the road as per a normal new road or rehabilitation design. The category of road will also determine the accuracy of design (e.g., [26,27]) as well as the required structural and functional characteristics which must be addressed through the application of normally accepted guideline documents developed and used throughout the world in various countries.

As an introduction to and for the understanding of the relevance of the construction techniques, the comparative design catalogue (design pavement structures for design traffic loadings of 1 million E80s to 30 million E80s) and the material requirements are repeated in Figure 2 [6,7], Figure 3 [6,7], and Figure 4 [27]. It should be noted that the application of the NME technology is not limited to 30 million E80s. The APT results (tests performed by the South African CSIR $[17,18])$ have demonstrated that designs can, with ease, be done for traffic loadings to at least a 100 million E80s. The design of LVR and access roads have also been addressed in more detail in a comprehensive design document applicable to all environmental climatic zones of the world [27], with the applicable materials criteria summarised in Figure 4 [27]. 


\begin{tabular}{|c|c|c|c|c|c|c|c|c|}
\hline \multirow{3}{*}{$\begin{array}{l}\text { Design traffic } \\
\text { Loading } \\
\text { Million } \\
\text { Equivalent } \\
\text { Standard } \\
\text { Axles }\end{array}$} & \multirow{3}{*}{\begin{tabular}{|c|} 
Typical \\
road \\
Category
\end{tabular}} & \multicolumn{4}{|c|}{$\begin{array}{c}\text { Recommended Pavement structure - Traditional 1980s design" } \\
\text { (Material classification - draft TRH14 (1987) - Layer thicknesses in mm) }\end{array}$} & \multirow{3}{*}{\multicolumn{3}{|c|}{$\begin{array}{c}\text { Alternative NME design } \\
\text { Pavem ent structure with naturally av ailable (in-situ) materi als } \\
\text { stabilised with a material compatible New -age Modified } \\
\text { Emulsion (NME) meeting the minunum specifications for the } \\
\text { stabilised material class }\end{array}$}} \\
\hline & & (draft TRH4) & \multirow{2}{*}{$\begin{array}{c}\text { (draft TRH4) } \\
\text { Gr anular Base } \\
\text { (Wet) }\end{array}$} & \multirow{2}{*}{ 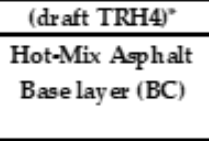 } & \multirow{2}{*}{$\frac{(\text { draft TRH4) }}{\text { Cem ented Base }}$} & & & \\
\hline & & Granular Base (Dry) & & & & & & \\
\hline \multirow[t]{6}{*}{ ES30 } & \multirow[t]{6}{*}{$\mathrm{A}^{*}$} & $40 \mathrm{~A}^{*}$ & $50 \mathrm{~A}^{*}$ & $25 \mathrm{~A}^{*}$ & & \multicolumn{3}{|c|}{$20 \mathrm{~mm}$ Cape Seal $\left(\mathrm{CS}^{1}\right) /$ Double seal $/ 30 \mathrm{~mm}$ Aspahalt ${ }^{2}$} \\
\hline & & $150 \mathrm{G}^{*}$ & $150 \mathrm{G}^{*}$ & $120 \mathrm{BC}$ & & 150 NME1* & 150 NME1$^{*}$ & 150 NME1* \\
\hline & & $125 \mathrm{C}^{*}$ & $200 \mathrm{C}^{*}$ & $200 \mathrm{C}^{*}$ & & $100 \mathrm{NME3}^{*}$ & $150 \mathrm{NME3}^{*}$ & 150 NME3* $^{*}$ \\
\hline & & $125 \mathrm{C3}^{*}$ & & $2003^{*}$ & & $150 \mathrm{G} 6^{*}$ & & \\
\hline & & & & & & & & $200 \mathrm{G7}^{*}$ \\
\hline & & $\mathrm{G} 7^{*}$ & G7* & G7* & & G9/G 8* & G9/G8* & $\mathrm{G} 10^{*}$ \\
\hline \multirow[t]{6}{*}{ ES10 } & \multirow[t]{6}{*}{$\mathbf{A} / \mathbf{B}^{*}$} & $40 \mathrm{~A}^{*}$ & $40 \mathrm{~A}^{*}$ & $40 \mathrm{~A}^{*}$ & & \multicolumn{3}{|c|}{$20 \mathrm{~mm}$ Cape Seal $\left(\mathrm{CSS}^{1}\right) /$ Double seal $/ 25 \mathrm{~mm}$ Aspahalt ${ }^{2}$} \\
\hline & & $150 \mathrm{G}^{*}$ & $150 \mathrm{G}^{*}$ & \multirow[b]{2}{*}{$150 \mathrm{C3}^{*}$} & & 100 NME2* & 100 NME2* $^{*}$ & 150 NME2* \\
\hline & & $125 \mathrm{C3}^{*}$ & $150 \mathrm{C}^{*}$ & & & 100 NME4* $^{*}$ & $150 \mathrm{NME4}^{*}$ & \multirow{2}{*}{150 NME4* $^{*}$} \\
\hline & & $125 \mathrm{C}^{*}$ & \multirow{2}{*}{$150 \mathrm{C}^{*}$} & $150 \mathrm{C}^{*}$ & & \multirow{2}{*}{$150 \mathrm{G} 6^{*}$} & \multirow{2}{*}{$150 \mathrm{G}^{*}$} & \\
\hline & & & & & & & & \\
\hline & & G7* & G7* & $\mathrm{G}^{*}$ & & G9/G8* & G9/G8* & G10* \\
\hline \multirow[t]{4}{*}{ ES3.0 } & \multirow[t]{4}{*}{$\mathrm{B}^{*}$} & $\mathrm{CS}^{1} / 30 \mathrm{~A}^{*}$ & $\mathrm{CS}^{1 / 30 \mathrm{~A}^{*}}$ & $30 \mathrm{~A}^{*}$ & $\mathrm{CS}^{1} / 40 \mathrm{~A}^{*}$ & \multicolumn{3}{|c|}{ Cape Seal $\left(10 / 14 / 20 \mathrm{CS}^{4}\right) /$ Double seal / $25 \mathrm{~mm}$ Aspahalt $\mathrm{t}^{2}$} \\
\hline & & $150 \mathrm{G}^{*}$ & $150 \mathrm{G} 1^{*}$ & $80 \mathrm{BC}$ & $125 \mathrm{C}^{*}$ & $100 \mathrm{NME4}^{*}$ & $150 \mathrm{NME}^{*}$ & \multirow{2}{*}{200 NME4* $^{*}$} \\
\hline & & $150 \mathrm{CA}^{*}$ & $150 \mathrm{C}^{*}$ & $200 \mathrm{C}^{*}$ & $200 \mathrm{C}^{*}$ & $150 \mathrm{G}^{*}$ & $150{\mathrm{G} 7^{*}}^{-3}$ & \\
\hline & & G7* & G7* & G7* & G7* & G9/G 8* & G9/G8* & $\mathrm{G} 10^{*}$ \\
\hline \multirow[t]{4}{*}{$<\mathrm{ES} 1.0$} & \multirow[t]{4}{*}{$\mathrm{C}^{*}$} & \begin{tabular}{|l|l|}
$\mathrm{CS}^{1} / 40 \mathrm{~A}^{*}$ \\
\end{tabular} & $\mathrm{CS}^{1} / 40 \mathrm{~A}^{*}$ & & $\mathrm{CS}^{1} / 40 \mathrm{~A}^{*}$ & \multicolumn{3}{|c|}{ Cape Seal $\left(10 / 14 / 20 \mathrm{CS}^{1}\right) /$ Double seal $/ 25 \mathrm{~mm}$ Asphalt ${ }^{2}$} \\
\hline & & $125 \mathrm{G}^{*}$ & $125 \mathrm{G}^{*}$ & & $125 \mathrm{C}^{*}$ & 100 NME4 $^{*}$ & 100 NME4 $^{*}$ & 150 NME4* \\
\hline & & $125 \mathrm{C}^{*}$ & $150 \mathrm{C}^{*}$ & & $125 \mathrm{CA}^{*}$ & $100 \mathrm{G}^{*}$ & $150 \mathrm{G}^{*}$ & \\
\hline & & G7* & $\mathrm{G} 7^{*}$ & & G7* & G9/G 8* & G9/G8* & G10* \\
\hline $\begin{array}{l}\text { Appropriate } \\
\text { econmended } \\
\text { inder with b } \\
\text { uavalent red }\end{array}$ & $\begin{array}{l}\text { eal accor } \\
\text { Seal: Cape }\end{array}$ & $\begin{array}{l}\text { ding to requirements }(1 \\
\text { Seal with a } 10 \mathrm{~mm} \text { or } \\
\text { modification to proted } \\
\text { he thickness of the NN }\end{array}$ & $\begin{array}{l}\text { n/Rural/Require } \\
\text { un stone or } 20 \mathrm{~m}\end{array}$ & $\begin{array}{l}\text { rfacing life/Labou } \\
\text { one; }\end{array}$ & ansive constuct & zone - as & place of a s. & onsidered for an \\
\hline
\end{tabular}

Figure 2. References [6,7]: Comparative pavement designs based on high-quality crushed +/or cement-treated materials with relatively thin surfacings and the newly recommended NME-stabilised designs using naturally available materials. ( ${ }^{*}$ Typical examples of recommended pavement structures taken from the draft TRH4 [22] with material classification according to TRH14 [23] (A = Asphalt; CS = Chip-seal; C = Cement stabilisation; G = Granular materials (Figure 1) NME $=$ New-age Modified Emulsions (Figures 3 and 4)) 


\begin{tabular}{|c|c|c|c|c|c|}
\hline \multirow[b]{2}{*}{ Test or Indicator } & \multirow[b]{2}{*}{ Material ${ }^{1}$} & \multicolumn{4}{|c|}{ Material classification } \\
\hline & & NME1 & NME2 & NME3 & NME4 \\
\hline \multicolumn{6}{|c|}{ Minimum material requirements before stabilisation and/or treatment (Natural materials) } \\
\hline \multirow{2}{*}{$\begin{array}{l}\text { Material spec.(minimum) } \\
\text { Unestablished material: } \\
\text { Soaked CBR } 2 \%) \\
\text { (Mod AASHTO) }\end{array}$} & \multirow[b]{2}{*}{ NG $/(\mathrm{CS})$} & $>45^{2}(95 \%)$ & \multirow[b]{2}{*}{$\begin{array}{l}>25^{2} \\
(95 \%)\end{array}$} & \multirow[b]{2}{*}{$\begin{array}{r}>10^{2} \\
(93 \%)\end{array}$} & \multirow[b]{2}{*}{$\begin{array}{c}>7^{2} \\
(93 \%)\end{array}$} \\
\hline & & $A C V<30 \%$ & & & \\
\hline \multirow{2}{*}{ Grading Modulus (GM) } & NG & $>1.8$ & $>1.5$ & - & - \\
\hline & GS & NA & $>1.5$ & - & - \\
\hline Sieve analysis: $\%<0.075 \mathrm{~mm}\left(\mathrm{P}_{0.075}\right)$ & ALL & $<20 \%$ & $<25 \%$ & $<35 \%$ & $<50 \%$ \\
\hline $\begin{array}{l}\text { XRD scans: } \\
\text { - Total sample } \\
-0.075 \mathrm{~mm} \text { fraction }\left(\mathrm{P}_{0.075}\right)\end{array}$ & $\begin{array}{l}\text { ALL } \\
\text { ALL }\end{array}$ & $\begin{array}{l}\sqrt{ } \\
\sqrt{ }\end{array}$ & $\begin{array}{l}\sqrt{ } \\
\sqrt{ }\end{array}$ & $\begin{array}{l}\sqrt{ } \\
\sqrt{ }\end{array}$ & $\begin{array}{l}\sqrt{ } \\
\sqrt{ }\end{array}$ \\
\hline \multirow{6}{*}{$\begin{array}{l}\text { \% Material passing } 2 \mu \mathrm{m}\left(\mathrm{P}_{0.002}\right) \text { (e.g. } \\
\text { Clay \& Mica \& Talc) as a } \% \text { of Material } \\
\text { (with Talc }<10 \% \text { ) } \\
\text { (XRD-scans of the material passing } \\
\text { the } 0.075 \mathrm{~mm} \text { sieve is used to } \\
\text { determine the } \% \text { clay, mica } \\
\text { (muscovite) and talc in the material - } \\
\text { In this case } \mathrm{P}_{0.002}=\mathrm{P}_{0.075} \times\left(\mathrm{P}_{\text {day }} \text { exc in }\right. \\
\mathrm{P}_{0.075} \text { ) }\end{array}$} & \multicolumn{5}{|c|}{ NME stabilisation with micro-meter $(\mu \mathrm{m})$ emulsion particle sizes } \\
\hline & ALL & $<15 \%$ & $<15 \%$ & $<15 \%$ & $<15 \%$ \\
\hline & \multicolumn{5}{|c|}{$\begin{array}{l}\text { NME stabilisation with emulsion containing micro-scale as well as nano- } \\
\text { scale particles (adjusted according to material grading) }\end{array}$} \\
\hline & ALL & NA & $<35 \%$ & $<35 \%$ & $<35 \%$ \\
\hline & \multicolumn{5}{|c|}{$\begin{array}{c}\text { NME stabilisation with emulsion containing nano-scale and pico-scale } \\
\text { particles (grading adjustments) together with technologies addressing } \\
\text { workability of materials on site }\end{array}$} \\
\hline & ALL & NA & NA & $>35 \%$ & $>35 \%$ \\
\hline \multicolumn{6}{|c|}{ Material specifications after stabilis ation and/or treatment } \\
\hline \multirow{2}{*}{$\begin{array}{l}\text { In-situ den sity to be re quired after } \\
\text { stabilisation and compaction (mod } \\
\text { AASHTO) (\%) (minimum) }\end{array}$} & Base & $>100 \%$ & $>100 \%$ & $>98 \%$ & $>97 \%$ \\
\hline & Sub-base & NA & $>98 \%$ & $>97 \%$ & $>95 \%$ \\
\hline $\begin{array}{l}\mathrm{DCP}(\mathrm{DN} \mathrm{mm} / \text { blow)(Quality } \\
\text { control) } \\
\text { (stabilised and compacted) }\end{array}$ & & NA & NA & $<2.6$ & $<3.5$ \\
\hline $\begin{array}{l}\text { Mod AASHTO density (\%) } \\
\text { (for laboratory te sting) }\end{array}$ & & $>100 \%$ & $>100 \%$ & $>100 \%$ & $>100 \%$ \\
\hline \multirow{2}{*}{$\begin{array}{l}{ }^{*} \mathrm{UCS}_{\text {wet }}(\mathrm{kPa}) \\
(150 \mathrm{~mm} \text { Ф Sample) }\end{array}$} & Design $^{3}$ & $>2500$ & $>1500$ & $>1000$ & $>750$ \\
\hline & Construction $^{4}$ & $>2200$ & $>1200^{5}$ & $>700^{5}$ & $>450^{5}$ \\
\hline $\begin{array}{l}\text { Retained Compressive Strength } \\
\text { (RCS): (UCS Swet UCSdry) (\%) }\end{array}$ & & $>85$ & $>75$ & $>70$ & $>65$ \\
\hline $\begin{array}{l}\text { RCS in relation to minimum } \\
\text { UCS } \\
\left(\mathrm{RCS} \text { x }\left(\text { oriteria) }=\mathrm{RCS}_{\text {efective }}=\right.\right. \\
(\%)\end{array}$ & & $>100$ & $>100$ & $>100$ & $>100$ \\
\hline \multirow{2}{*}{${ }^{\star} \mid \mathrm{TS}_{\text {wet }}(\mathrm{kPa})(150 \mathrm{~mm} \Phi$ Sample) } & Design $^{3}$ & $>240$ & $>200$ & $>160$ & $>120$ \\
\hline & Construction $^{4}$ & $>220$ & $>180^{5}$ & $>140^{5}$ & $>100^{5}$ \\
\hline $\begin{array}{l}\text { Retained Tensile strength (RTS): } \\
\text { ITS } \\
\text { ITed IT Sdry }(\%)\end{array}$ & & $>85$ & $>75$ & $>70$ & $>65$ \\
\hline 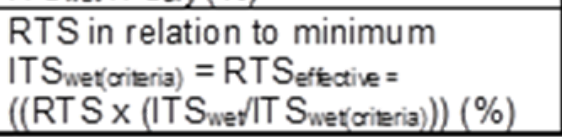 & & $>100$ & $>100$ & $>100$ & $>100$ \\
\hline \multicolumn{6}{|c|}{ 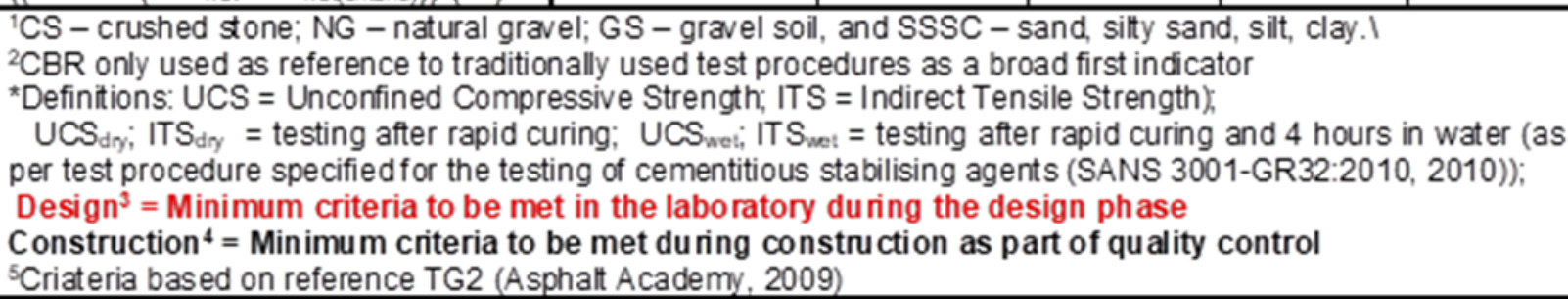 } \\
\hline
\end{tabular}

Figure 3. References [6,7]: Minimum recommended standard specifications for New-age (Nano) Modified (NME) stabilised materials, addressing four different classifications in terms of engineering requirements. 
From the comparative design catalogue (Figure 2), it is seen that for the higher-order roads using conventional designs, a high-quality crushed stone (G1, G2, and G3 (Figure 1)) material is prescribed for the construction of the base-layer (as an alternative to full-depth asphalt designs) [28]. These materials are usually only available from commercial sources at a considerable cost which, in addition, is also associated with haulage costs that could be substantial depending on the availability of the material relative to the distance from the construction site. Haulage costs may be a major factor in areas between the tropics close to the equator and in desert areas where sources of high-quality crushed stone may be a scarce commodity. In comparison, naturally available materials (gravels of a G4 to G9 quality (refer Figure 1) or sand of various gradings) may be more readily available close to construction sites. The use of the naturally available granular materials, together with a material-compatible anionic NME stabilising agent, may result in considerable savings in material costs as a basic input into a probabilistic life-cycle cost analysis approach [29], taking into account the associated risks.

Naturally available materials close to but not meeting the classification criteria/ properties of freshly crushed stone usually still contain a solid core of primary minerals with some presence (relatively small percentages) of secondary minerals which developed as a result of some chemical weathering [6,7]. The neutralisation of any possible negative effect of these secondary minerals, using applicable nanotechnologies, are relatively easy to achieve by following the recommended materials design method [6].

The opposite is the case with materials of very poor quality as defined for use in road pavement structures (these materials may be classified as very good for purposes such as agriculture). In these cases, the bulk of the naturally available material may consist of secondary minerals with the structure of the particles of the primary minerals already compromised due to the process of chemical weathering [6]. It follows that the crushing strength of the primary minerals present in the naturally available materials may already have been compromised. Although more complicated, the characteristics of these materials can also substantially be improved using applicable nanotechnologies $[6,7,12]$. In these cases, the material may be improved for use in the upper layers (base and/or sub-base of roads with design traffic loading up the 10 million E80s [16-18,27]) or in the supporting layers of pavement structures with higher design traffic loadings.

G3 to G6 (Figure 1) materials are considered marginal or unacceptable for use in baselayers of roads with a design loading in excess of 3 million E80s. However, in combination with a material-compatible anionic NME stabilisation agent, the quality of such material can chemically be improved to be suitable for use in the base and sub-base-layers of these roads. Depending on the mineralogy of the materials and the implementation of a scientifically based materials design approach $[6,7,12]$, a material-compatible anionic NME stabilising agent can be used with confidence with G3 to G6 materials to meet all engineering specifications for design traffic loadings in excess of 10 million E80s without compromising the integrity of the pavement structure. A material-compatible anionic NME stabilising agent will protect every particle of the granular material used in the construction of the pavement layers, from the detrimental effect and access to the moisture (water). Hence, possible future chemical weathering is eliminated [12,13] and long-term in situ pavement durability improved with an associated reduction in future periodic maintenance requirements.

\section{Basic Site-Related Requirements to Ease the Construction of NME Stabilisation}

Construction operations, especially in the developing regions of the world, often present contractors with severe challenges in terms of various factors unfamiliar to the developing world, including:

- Logistical problems getting materials timeously on site due to logistical challenges presented by infrastructure and climatic conditions, as well as by limited production facilities; 
- Maintenance problems with regard to construction equipment (limited access to spare parts);

- Uncertainties with regard to sureties and irregular payments; and

- Community factors as a result of high unemployment rates as well as factional (political) influences and related delays due to often unrealistic expectations of employment created in areas with high needs and poverty, etc.

All of these challenging conditions require that a basic requirement of any product delivered for the stabilisation/enhancement of naturally available granular materials must be of a proven stability and resiliency in nature in these areas. Suppliers need to guarantee these basic requirements (e.g., stability and application at ambient temperatures) of any NME stabilising agent for lengthy periods of time under extreme climatic conditions. These conditions may often include limitations in the ability of the regular maintenance of the stabilising agent (e.g., circulation of the stabilising agent stored in flow-bins or tankers in the sun under challenging conditions). These requirements should be addressed clearly in special provisions within contract specifications, requiring contractors and their suppliers to guarantee the stability of the NME stabilising agent over a period of time (minimum recommended storage time of 4 months), as dictated by local conditions.

Any specified NME stabilising agent must be able to be:

- Applied at ambient temperatures without prior heating and circulation, and mixed with the construction water with ease to enable quick and reliant distribution as well as mixing; and

- Of a quality that ensures that particle sizes of the NME are minimised to facilitate ease of distribution within the construction water, resulting in minimum risks of blockages to nozzles of equipment (e.g., of water-bowser and/or recyclers, etc.), provided that the equipment is clean at the start of operations (construction water should also be clear of any possible particles that may cause obstructions).

These basic requirements will prevent additional complicated heating operations (and related costs) and frequent delays caused by blockages of equipment which will require frequent cleaning operations and costly stoppages, and/or construction problems. Practical experience in southern Africa has shown that high-quality material-compatible anionic NME stabilising agents are able to meet these conditions with ease provided that special conditions of contracts $[7,27]$ are strictly adhered to and adequate quality control measures are in place.

\section{Construction of NME Stabilised Granular Pavement Layers-Practical Aspects}

\subsection{Weather Conditions}

Weather conditions and limitations to construction as per normal road construction projects are applicable to the construction of road pavement layers using NME stabilising agents. The NME stabilising agents must be added to the construction water prior to the addition thereof to the granular materials that are being stabilised. The in-situ moisture of the materials will determine the total construction water required (together with the stabilising agent) in order to achieve optimum construction compaction conditions. Experience has shown that the best conditions are normally achieved at moisture contents just below Optimum Moisture Contents (OMC). Hence, it is recommended that the total of the added fluid content of the NME stabilising agent be taken into account in the calculation of the required construction water to be added.

For example, if the OMC of the granular material to be stabilised is 8 percent and the granular material to be stabilised contains 5 percent moisture, the construction water with the NME stabilising agent to be added is $(8-5) 3$ percent. In the case where the required designed percentage of the material-compatible NME stabilising agent is 1 percent, it had to be mixed with an additional $2(3-1)$ percent of construction water within the water-bowser prior to the stabilisation of the granular materials. Some modern recycling equipment allows for more than one feed into the recycler. Under no circumstances should the NME stabilising agent and construction water be fed into such equipment separately. Water in 
the carrier of the NME stabilising agent, the separate addition of water, and the stabilising agent will not allow for the even distribution of the NME stabilising agent within the granular material and hence the unsuccessful stabilisation of the pavement layer.

Depending on local conditions (e.g., very hot days), allowance should be made for the evaporation of water during the stabilising process by increasing the percentage of construction water that will evaporate during the process of mixing and compaction as a function of the:

- Type of construction equipment used (some construction equipment will take considerably longer to thoroughly mix the stabilising agent with the granular material, resulting in higher loss of moisture);

- Prevailing temperature and humidity during the stabilisation process; and

- Delays on site as a result of logistical supply problems.

\subsection{Delivery to and Storage of the NME Stabilising Agent at a Road Construction Site}

The NME stabilising agent is normally delivered to the site in 1000 litre flow-bins (Figure 5a) or using bulk storage tankers varying in size from 15,000 to 30,000 litres (Figure 5d). Although it is often stipulated by supplier-to-store flow-bins or tankers in shade, in reality, this seldom happens. However, experience has shown that high-quantity anionic NME stabilising agents will be able to stay stable with no visible sign of separation of the various components and/or increase in the measured viscosity under harsh climatic conditions with daily temperatures exceeding $35^{\circ} \mathrm{C}$ in the open with no shading (Figure $5 b$ ) for more than 4 months. It is recommended that a guarantee of at least 4 months be required from a supplier for a delivered NME stabilising agent in a flow-bin to remain in a stable condition with no signs of separation. In big tankers fitted with a simple circulating pump, a high-quality anionic stabilising agent has been shown to stay stable with no increase in viscosity for periods exceeding 12 months with a once-a-week maintenance (circulation using the fitted circulation pump).

NME stabilising agents have a relatively low viscosity, making it easy to be added to the construction water in a water-bowser by simply using gravity. Figure $5 c$ shows the lifting of a flow-bin with the NME stabilising agent above the intake of the water-bowser, allowing the NME to be added to the construction water. Alternatively, a simple pump with a measuring device can be used to deliver the required volume of the NME stabilising agent to the water-bowser, as would be required in the case of the use of bulk takers, such as those shown in Figure $5 \mathrm{~d}$.

\subsection{Clean Equipment}

A pre-requisite to the successful application of an NME stabilising agent is the use thoroughly cleaned equipment. Although contractors are made aware of this aspect, it is, almost without exception, found that the first day of operations present problems with the use of equipment containing residue from previous operations. The organo-functional silane-modification to a stabilising agent is a re-active agent that will react with any residue left in a water-bowsers, etc., from previous operations. It has become the norm to expect reactions (as shown in Figure 6) questioning the quality of the stabilising agent when the NME stabilising agent is added to uncleaned water-bowsers, resulting in the formation of "blobs" or sticky substances of bituminous materials that are unusual. In order to prevent such first day occurrences, it is recommended that equipment be inspected before being used on site for NME stabilisation purposes. Figure $6 \mathrm{a}, \mathrm{b}$ shows some results of pre-inspections done on "clean" equipment. 


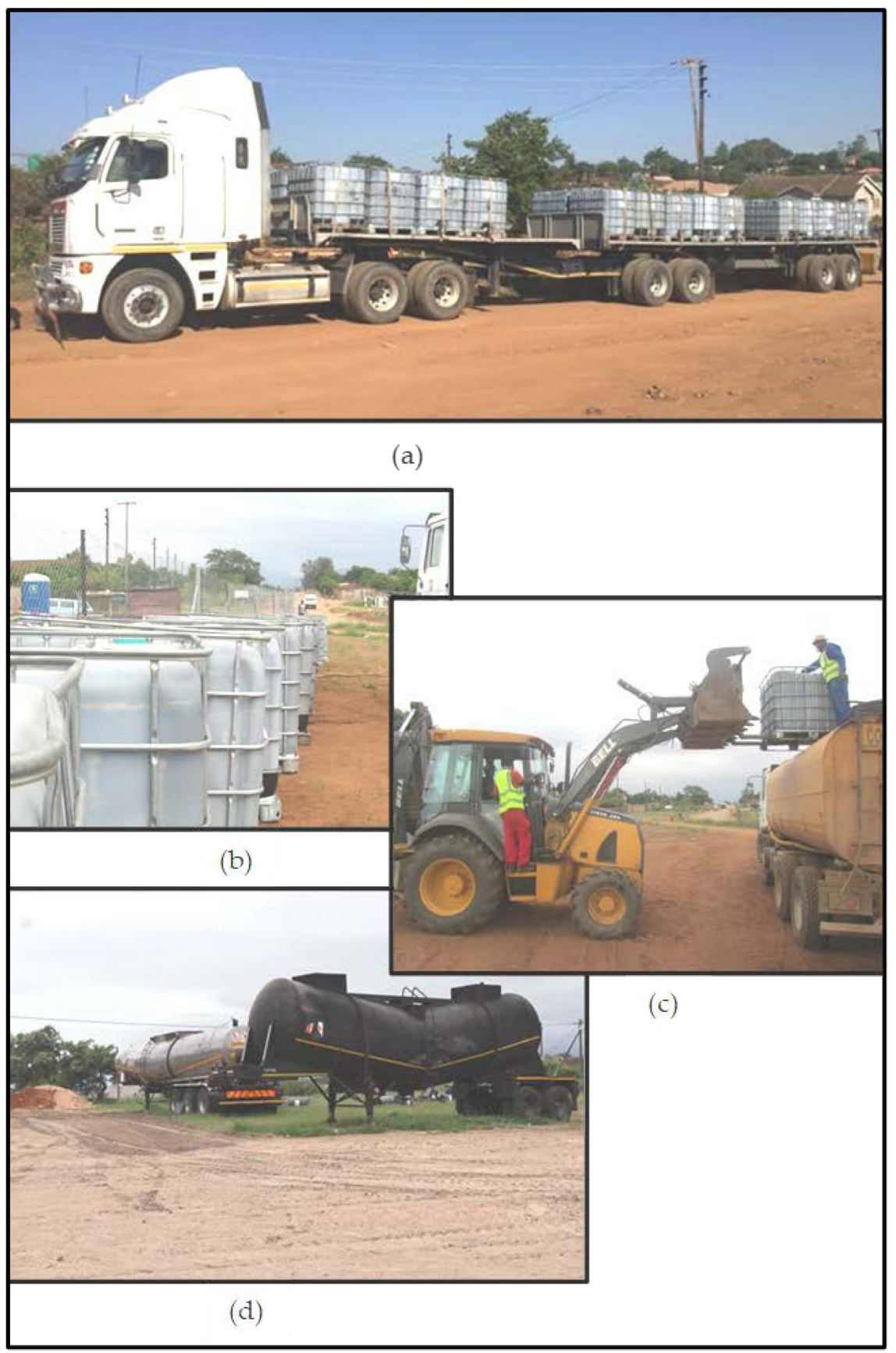

Figure 5. (a) Arriving on site of material-compatible anionic NME stabilising agents in 1000 L flowbins. (b) Flow-bins containing a high-quality anionic NME stabilising agent exposed to high daily temperature. (c) NME stabilising agent delivered to construction water in water-bowser by lifting the flow-bit above the water-bowser and using gravity. (d) NME stabilising agent delivered to site in bulk tankers. 


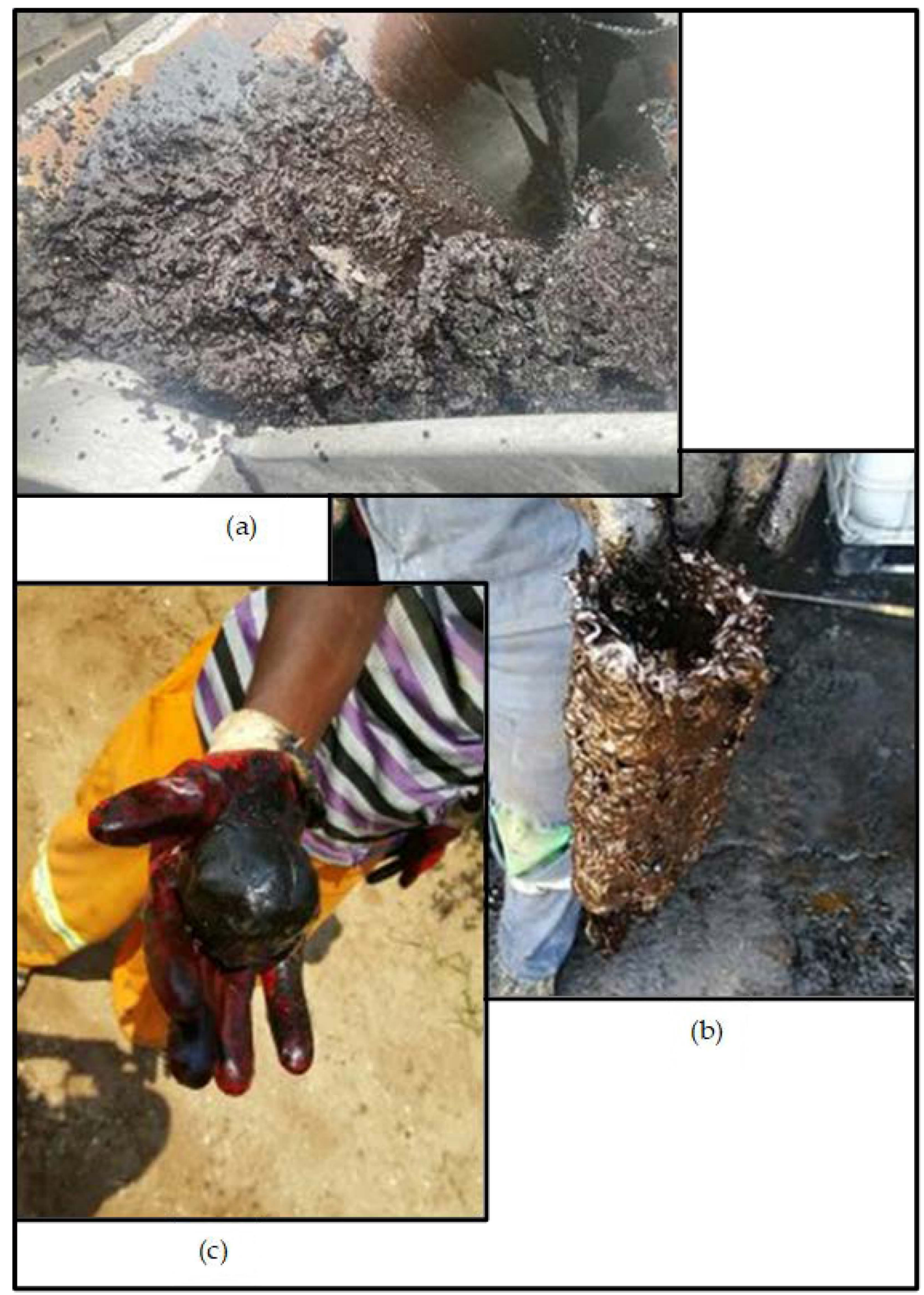

Figure 6. $(\mathbf{a}, \mathbf{b})$ Typical examples of residue and the state of equipment found during the pre-inspection of "clean" equipment of contractors for use for the stabilisation of granular materials using an anionic NME stabilising agent. (c) Typical example of an anionic NME stabilising agent that has been added to the construction water-bowser containing residue from previous operations, resulting in a reaction with the residue, resulting in an unusable "blob" of bituminous material. 


\section{Common Construction Operations Suitable for the Stabilisation of Granular Materials Using NME Stabilising Agents with Granular Materials}

\subsection{General}

The construction of highways, the rehabilitation of existing roads, or the upgrading of rural gravel roads using in situ materials stabilised with an anionic NME stabilising agent lends itself towards the utilisation of a full complement of construction methods. Depending on the specific requirements (over and above the designed material end-product specifications) and the needs of the implementing agency or the funding agency, the pavement structure and surfacing can be done using any:

- Fully mechanised, high-accuracy, centralised mixing plants together with high-accuracy placement with laser-controlled paving equipment;

- Sophisticated recyclers equipped with mini-computers to control the application of the stabilising agent;

- Conventional equipment consisting of basic water-bowsers, graders for mixing, and compaction equipment able to meet the basic density specifications; or

- Construction procedures aimed at the maximisation of labour-enhanced construction methods together with suitable compaction equipment. When requiring labourintensive construction operations, a mixture of suitable equipment with a high-labour content, together with specific applicable design options (e.g., type of surfacing), usually proves to be the most cost-effective. These requirements are usually a function of external requirements [18].

The construction methods mentioned above for road construction are nothing new. However, the applicability of these different construction methods is of importance when the industry is faced with the introduction of new technologies. Recent (over the last 5 years) experience has addressed this very issue when contractors attempted claims on the basis that NME stabilisation required specialised equipment not foreseen or specified for the successful stabilisation of granular materials using an NME stabilising agent. For this very reason, it is important to document actual projects using the various construction methods where NME stabilisation with traditionally categorised "marginal" or "unsuitable" granular materials has successfully been executed, meeting all engineering requirements.

It is important to note that all the examples shown and implemented have been preceded by a design procedure addressing the technical and non-technical requirements of a specific road (e.g., [22,26]), which may or may not influence the construction process to be adopted. Depending on these needs and following a materials design method [6], based on the fundamental science of mineralogy and chemistry with the modification to the stabilising agent [12,13], a life-cycle cost comparison of applicable options incorporating probabilistic theory [29] will enable the designer to recommend the most cost-effective applicable option for implementation. In compliance with the approved design, projectspecific Terms of Reference (TOR), Bill Of Quantities (BOQ), and project-specific special provisions must be compiled for open-tender processes (where applicable). These documents will be used by contractors to determine the most cost-effective equipment to utilise and submit tenders based on the requirements of a specific contract.

With high rates of unemployment in developing countries being a major factor, external influences often require bulk infrastructure programmes to address projects, with the emphasis on the provision of opportunities for employment as well as on the creation and development of small enterprises. In such cases, it is recommended that the implementing agency adjust policies in order to sign separate session agreements with material suppliers and equipment rental agencies for direct payment by the implementing agency. The BOQ should be adjusted to require emerging contractors to price works based on the execution of the works only. Tenders for material suppliers should be based on end-product specifications, requiring suppliers to meet specified minimum requirements in terms of the stability of stabilising agents and meeting minimum engineering end-product criteria using the available materials as supplied. Allowance should be made for suppliers to have access to materials to design and optimise material-compatible stabilising agents $[6,27]$. In the 
case of labour-enhanced construction methods, adequate provision should be included for experienced supervision of the work, with personnel able to accommodate technology transfer as part of their duties.

Construction equipment successfully used on actual projects for the construction of NME-stabilised granular material pavement layers is discussed in the same sequence identified above, starting with the use of centralised mixing plants and constructing the base-layer of a multi-lane inter-city highway using a laser-controlled paver within a tolerance of $2 \mathrm{~mm}$. The practical implementation and discussions of these construction methods and related equipment involves some considerations with regard to the advantages and disadvantages associated with the methods and equipment.

\subsection{Central Plant Mixing and Construction of Pavement Layers Using Paving Equipment}

As discussed previously, the use of marginal materials and stabilisation/enhancement thereof is not restricted to lower-order roads. The use on crushed stone materials protected by the addition of small percentages of an anionic NME can be beneficial both in terms of durability (prevention of in situ chemical decomposition) as well as the energy required to achieve the specified high levels of compaction [21-23]. Naturally available granular materials stabilised with a material-compatible anionic NME stabilising agent as per a scientifically based materials design process can also, with relative ease, meet the design requirement for inter-city and other highways, designed to carry relatively high traffic loadings as shown in Figure 2 [21], in association with Figure 3 [6]. These roads are associated with a high required constructed riding quality, ideally suited for construction using equipment able to deliver these requirements at a low risk to contractors.

The example shown involves the use of a central computerised mixing plant (Figure 7a) to prepare the granular material mixed with the construction water and an anionic NME stabilising agent. The central mixing plant automatically mixes the granular material (in this case, a G5/6 material-refer Figure 1) with a high degree of accuracy with the anionic NME stabilising agent (in the example-1.2 per cent, containing about 0.7 percent residual bitumen)) pre-mixed with the construction water to be delivered to trucks for transportation to the road under construction (Figure $7 \mathrm{~b}$ ). The water added to the mix should take into account any loss of moisture that may occur during the transportation of the mix to the construction site and the construction of the layer. In cases of a long haulage distance and/or high temperatures, it is standard procedure to cover the pre-mixed materials on the trucks to minimise the loss of moisture through evaporation during transportation.

On this specific project, the sub-base was constructed using the same granular material stabilised with 0.7 percent anionic NME ( \pm 0.4 percent residual bitumen) using conventional equipment (to be demonstrated). Note the curbs put in place for the inter-city freeway that is being constructed. Figure $7 \mathrm{~b}, \mathrm{c}$ shows the delivery of the NME-mixed granular material prepared in the central plant for placement by paver with the various compaction rollers ready for the compaction of the $150 \mathrm{~mm}$ thick base-layer (the small roller is used for compaction next to the curb, while the smooth drum vibratory roller ensures that the density requirements are met and, in combination, the pneumatic wheel roller ensures that a high-quality surface texture is achieved). Figure 8a-c shows the compaction of the base-layer and the final high-quality finishing of the base-layer after compaction. The hydrophobic nature (water repellent characteristics of the anionic NME stabilisation of the base-layer) is shown by the speed at which the moisture is effectively repelled from the layer. 


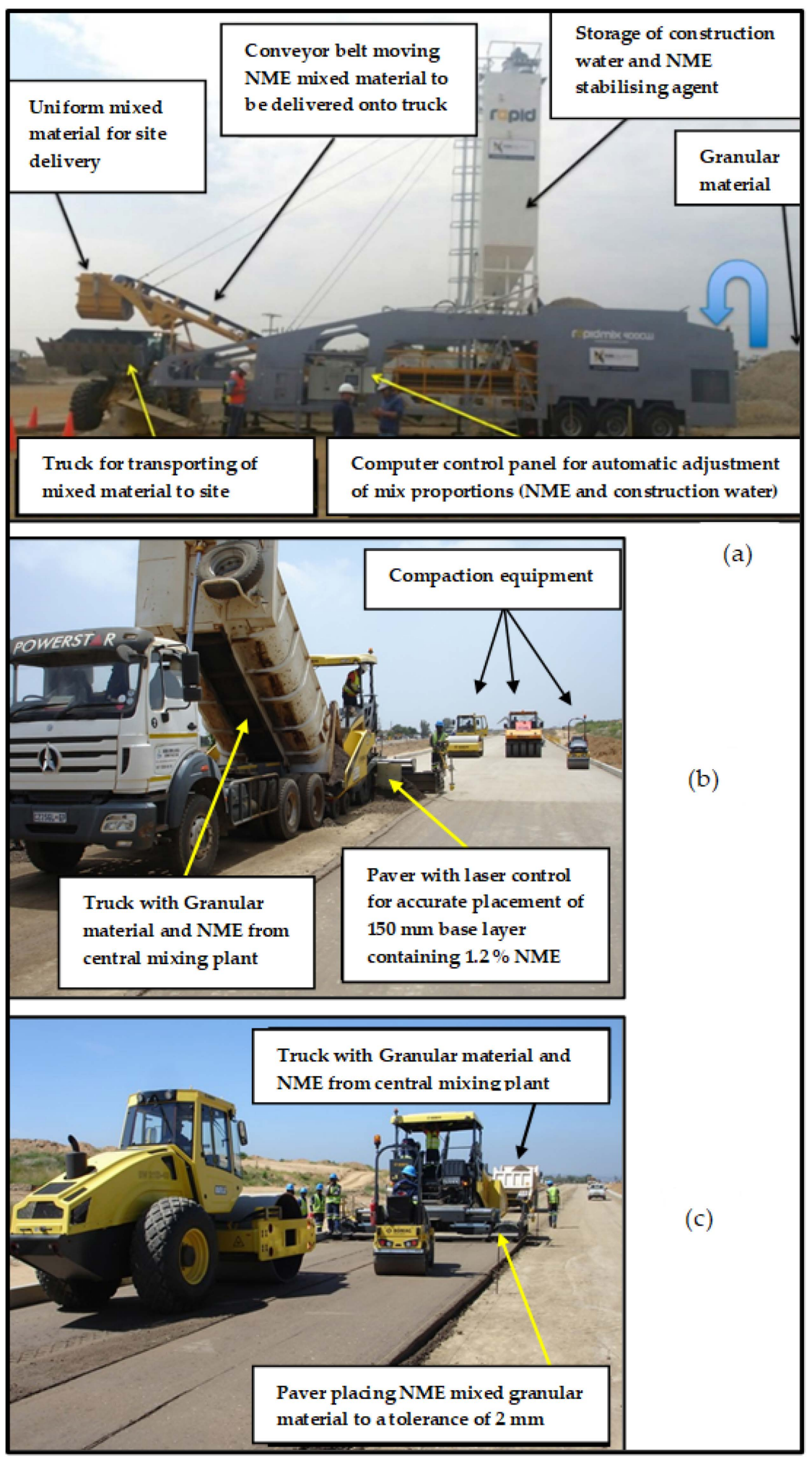

Figure 7. (a) Central mixing plant mixing the granular material with the required construction water containing the anionic NME stabilising agent for transportation to site; (b) delivering material in paver; and (c) compaction of base-layer. 


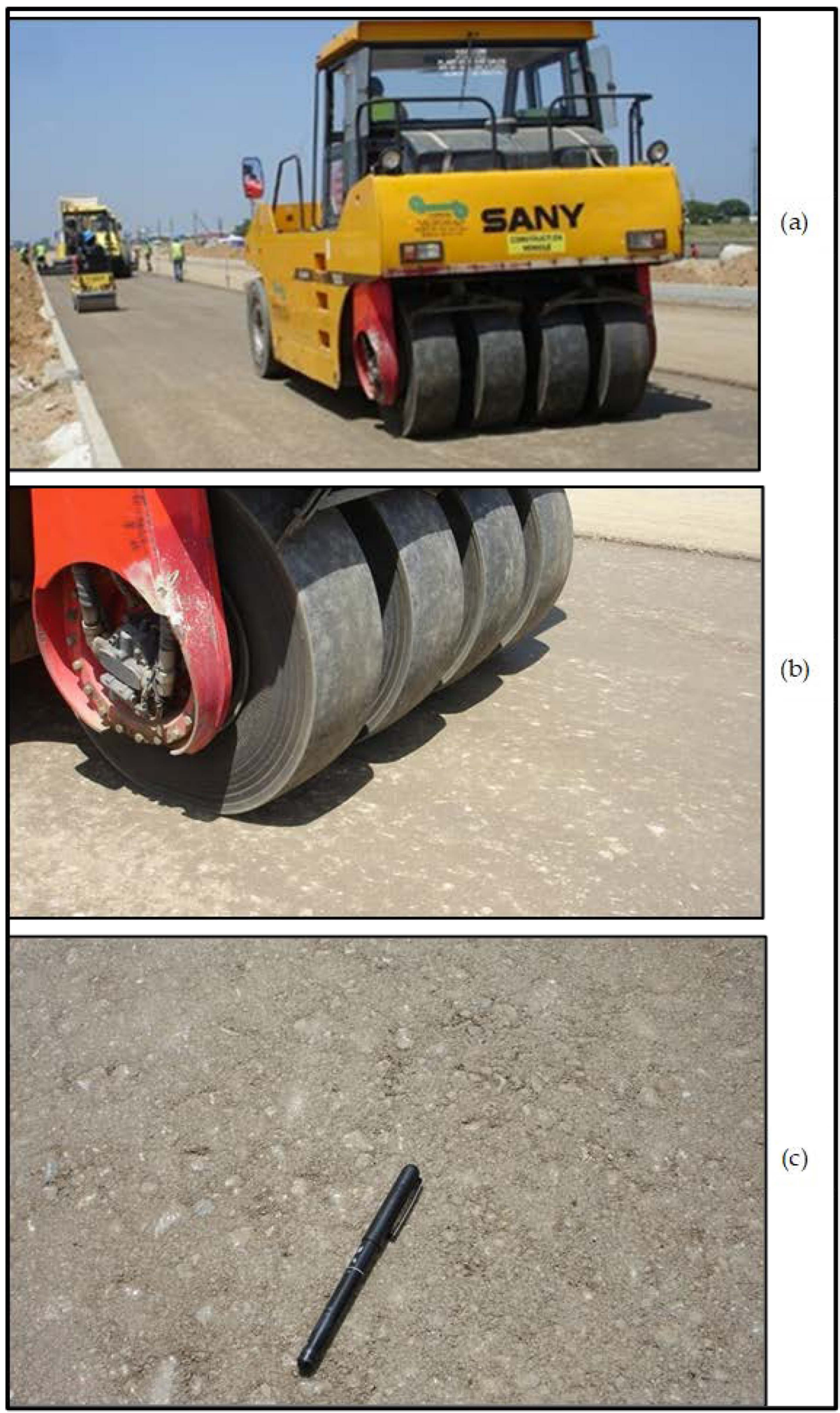

Figure 8. (a) Compaction of base-layer behind paver. (b) Final compaction with pneumatic roller to a high level of tolerance. (c) Achieved base texture with G5/G6 material with $1.2 \%$ anionic NME stabilising agent $(0.7 \%$ residual bitumen).

One week after construction of the base and sub-base (both exposed with no prime or surfacing was severely tested by nature). Within $48 \mathrm{~h}$, more than $200 \mathrm{~mm}$ of rain was reported on site with the sub-base (Figure 9a) and base (Figure 9b) representing rivers. The general consensus among the seasoned contractors, consultants, and the 
client was that the pavement layers would have been damaged to such an extent that reconstruction would be inevitable. However, after drying of the pavement layers, no damage was noted (Figure 9c). It is worth noticing that under similar conditions, experience dictates that with a crushed stone, cement-treated or normal emulsion-treated unprotected layers, reconstruction of the base-layer would, in all probability, have been required due to extensive water-related damage.

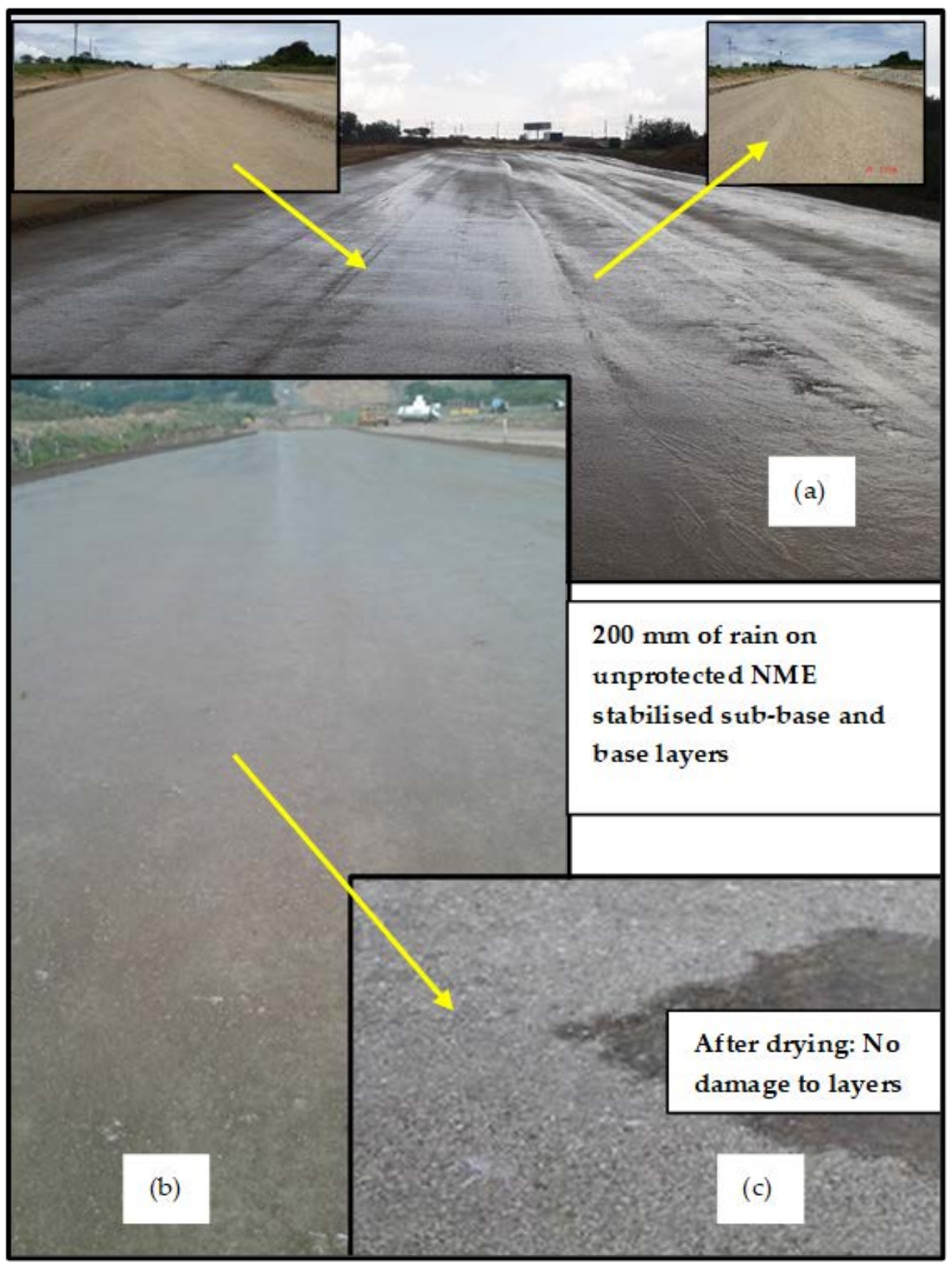

Figure 9. One week after placement of base $(1.2 \% \mathrm{NME}-0.7 \%$ residual bitumen) and the exposed sub-base (0.7\% NME- $0.4 \%$ residual bitumen), $200 \mathrm{~mm}$ of rain fell with (a) the sub-base-layer and (b) base-layer representing rivers. (c) After drying, no water-related damage could be observed.

\subsection{NME Stabilisation Using Recycling Equipment}

Centralised, computerised mixing equipment is generally not reliably available in most countries throughout the world. However, this does not exclude the use of anionic NME-stabilised naturally available materials from being used for the construction of 
highways or, for that matter, any other road. NME stabilisation lends itself towards road construction using basically any construction equipment. The finishing achieved using basic equipment is normally a function of the training and skills of the operators. The use of sophisticated equipment in road construction normally just simplifies operations and lends itself towards higher productivity and reduced construction periods. The use of modern recycling equipment can also be classified in the same category of equipment. Experience has shown that it is not unusual to stabilise a $1 \mathrm{~km}$ length, $10 \mathrm{~m}$ wide section of road with an anionic NME stabilising agent and to finish compaction within a single day. These production rates are achievable when all related logistical aspects are well planned and in place.

The NME stabilising agent is easily added to a water-bowser using gravity as shown in Figure $5 \mathrm{c}$. The water-bowser should already contain the required construction water for the section of the road, taking the volume of material into account as per previous discussion. The anionic NME stabilising agent will automatically disperse into the construction water to create a uniform mix for immediate use at ambient temperatures. No preheating of a quality anionic NME stabilising agent will be required for temperatures above freezing. The water quality could influence the stabilisation process and the normal water construction quality requirement specified for any other type of road construction is also applicable to NME stabilisation.

In order to control application rates using recyclers for the mixing of the construction water premixed with the NME stabilising agent, the recycler should be equipped with a microprocessor which will regulate the application of the stabilising agent with the speed of travelling. These requirements are standard with most manufacturers of modern recyclers, which also allows for the depth of stabilisation to be controlled with a high degree of accuracies. However, few recycler manufacturers used to have these automatic controls and it is still recommended that these basic requirements for recyclers should be written into project-specific specifications in order to pre-empt and prevent any construction-related dispute as to minimise equipment requirements.

Figure 10a shows the use of a recycler for the mixing of the stabilising agent and construction water with the granular material on the same highway shown in Figures 7 and 8. Note the uniformity of the mix at the back of the recycler, showing the good working order of the recycler with all nozzles fully in operation and no problems associated with the mixing drum or the supply of the NME stabilising agent pre-mixed with the construction water. Figure 10b shows the construction train used in the mixing and the compaction of a full width of a secondary road using an anionic NME stabilising agent.

The use of recyclers for the in-situ recycling and stabilisation of distressed roads using material-compatible anionic NME stabilising agents are especially a cost-effective procedure for the quick reinstatement of roads, with a minimum disruption to traffic and inconvenience to property owners in urban areas. Figures 11 and 12 show the rehabilitation of a severely distressed urban road through the in-situ recycling of the G7-quality base material mixed with the remainder of the surfacing material. The use of a recycler enabled a total of $6 \mathrm{~km}$ to be recycled and stabilised within 2 weeks. With only a quick drying with anionic diluted NME prime as a protection, the road remained open for almost two months over the summer holidays before the placement of a $30 \mathrm{~mm}$ thick asphalt surfacing, with a 60/70 pen bitumen modified with 3 percent Sasobit ${ }^{\circledR}$ as shown in Figures 13 and 14.

It should be noted that the use of the NME stabilising agent required:

- No cement to be pre-spread as per normal emulsion stabilisation, with a saving in time and risk under windy conditions;

- The resulting accelerated drying and opening of the road to local traffic; and

- Little damage to the base-layer over a period of two months with only a material compatible prime as a protective layer. 


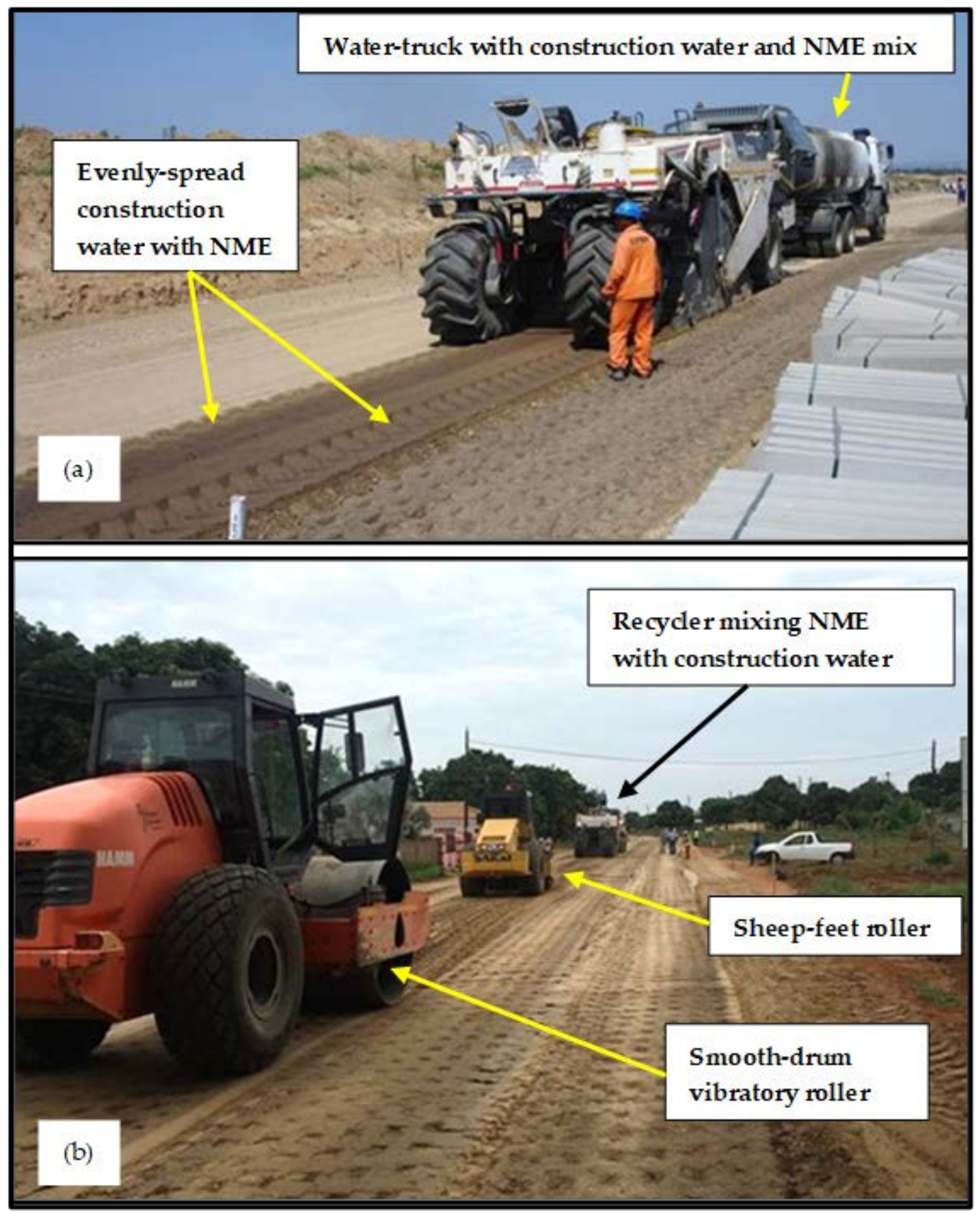

Figure 10. Mixing of the anionic NME stabilising agent using a recycler with a fitted micro-processor which controls the application of the NME stabilising agent pre-mixed with the construction water of the (a) inter-city highway. (b) Upgrading of urban road. 


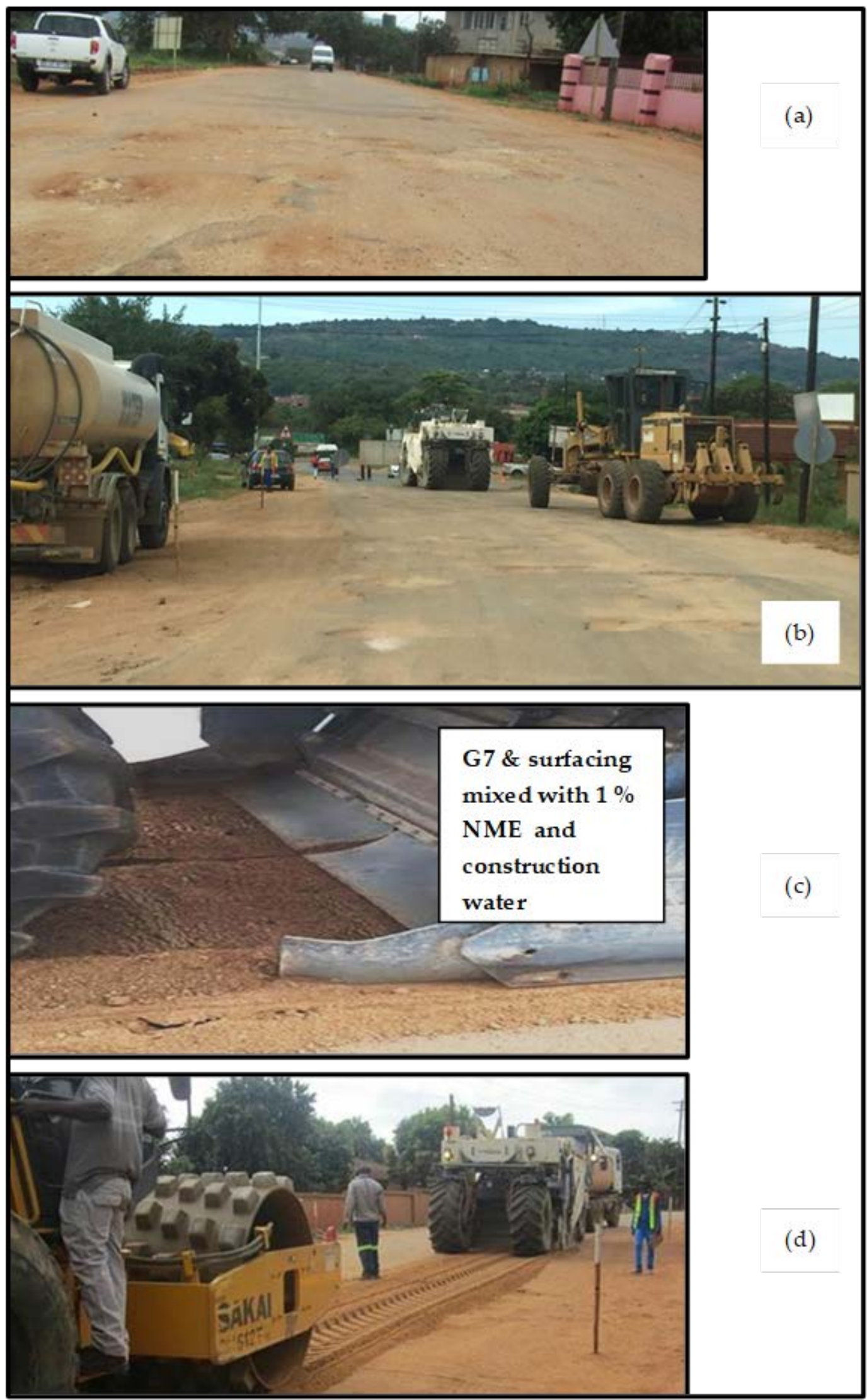

Figure 11. (a,b) Rehabilitation of a severely distressed urban road. (c,d) Mixing the surfacing with the in situ G7-quality base material with 1.0\% NME material-compatible stabilising agent within the construction water and the compaction to be opened to local traffic the same day. 


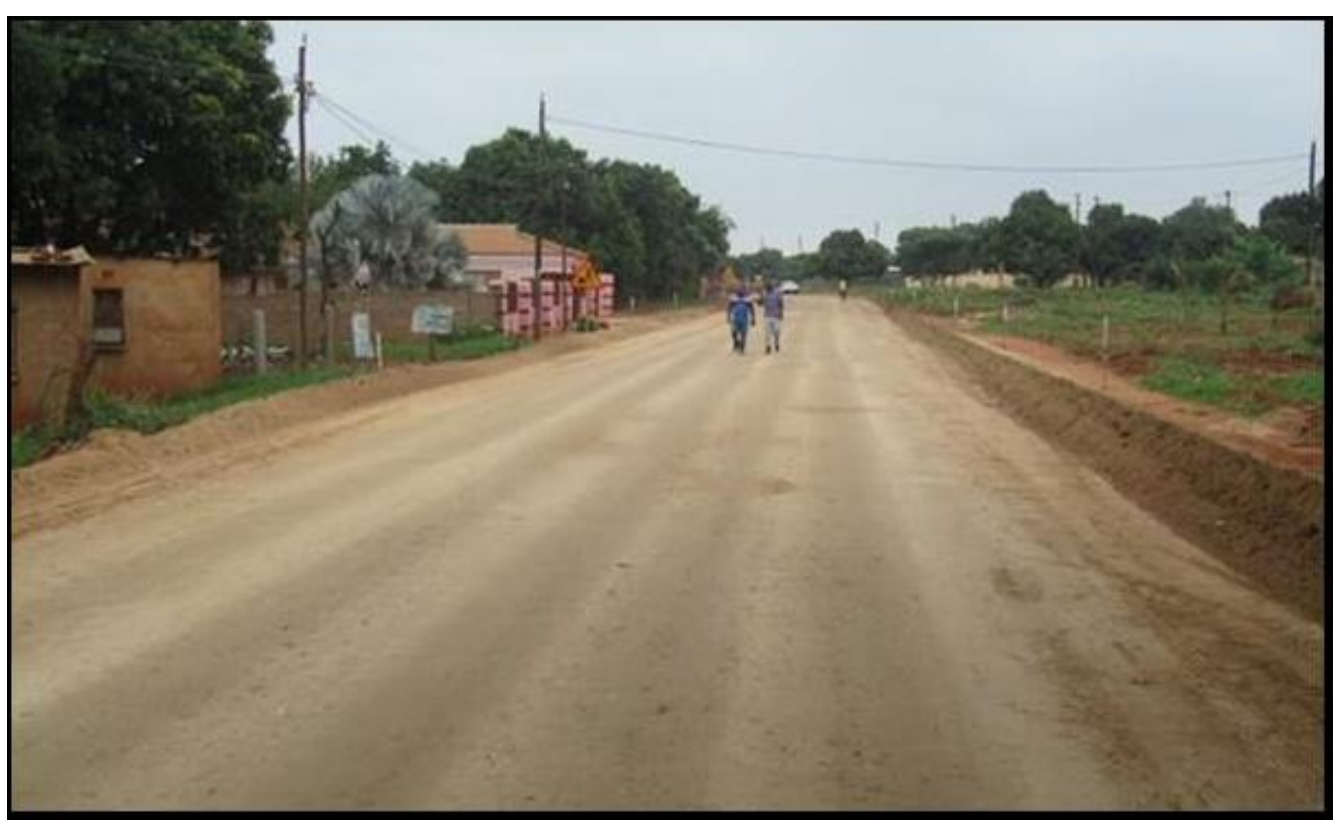

Figure 12. Recycled road with NME stabilisation opened to local traffic to provide access to houses, with no protective prime or surfacing added (note the same, pink-painted façade of the same house shown in Figure 11a).

\subsection{NME Stabilisation Using Conventional Mixing Equipment (Water-Bowser and Grader) \\ 6.4.1. General}

In the absence of any centralised mixing equipment and recycling equipment, traditionally used construction equipment generally used for the construction of granular road pavement layers are just as suitable for the NME stabilisation of naturally available materials. These traditional operations are equally applicable to the construction of highways, to secondary roads, as well as for the upgrading of gravel roads. No compromising of standards will be sacrificed by using traditional road construction equipment. As always, the final product delivered will be a function of the training and operational skills of the operators operating the various different pieces of equipment used to construct the road pavement layers. The use of conventional equipment on the various category of roads to the applicable standards is demonstrated through examples taken from highways to secondary roads and to local access roads requiring a relatively low LOS.

\subsubsection{Construction of Multi-Lane Dual Carriageway Highways}

The construction of the sub-base of the multi-lane highway shown in Figures 7 and 8 (using a centralised mixing plant) as well as in Figure 10a (using a recycler) for the construction of the NME-stabilised base-layer was constructed using conventional traditional road construction equipment, i.e.,:

- Water-bowser containing the anionic NME stabilising agent pre-mixed with the calculated construction water;

- Normal graders for the mixing and final cutting of the levels of the layer; and

- Conventional compaction equipment.

The construction of the sub-base-layer of the dual carriageway with 0.7 percent (about 0.4 percent residual bitumen) of a G5/6-quality material (refer Figure 1) using conventional construction equipment is shown in Figures 14 and 15. The anionic NME stabilising agent is pre-mixed with the calculated construction water as demonstrated in Figure 5. Of specific note after construction of the first road section is the comment made by one of the grader operators expecting that the use of the new-technology application would be difficult, stating "the process is nothing more than the construction of a normal granular layer using dirty water". 


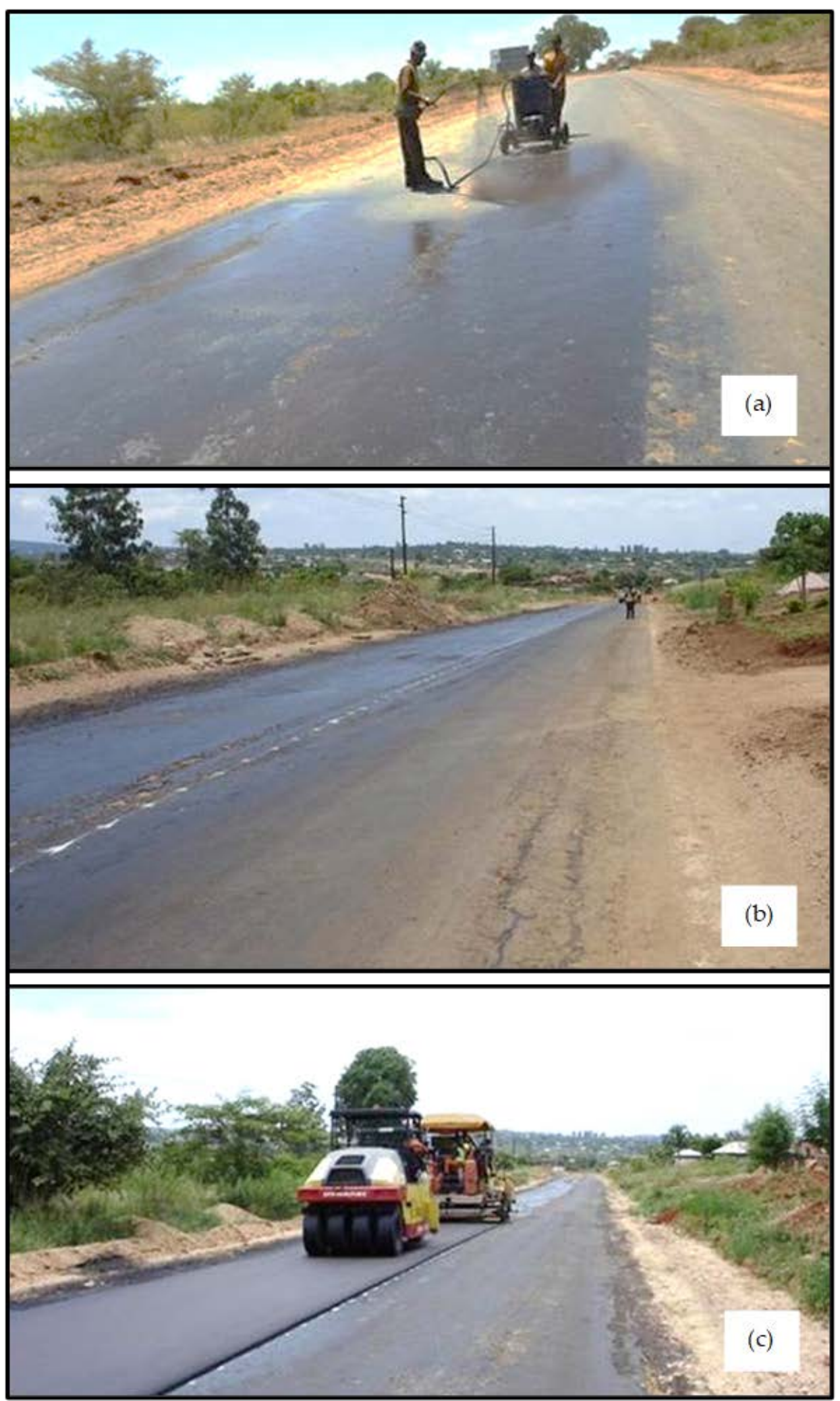

Figure 13. (a) Hand application of a quick-drying anionic-diluted NME prime coat to protect the base before application of the surfacing; (b) application of a tack coat 2 months after construction of the base-layer (opened to traffic); and (c) application of the surfacing. Note the little damage to the base-layer after two moths open to traffic during the holiday and rainy season. 


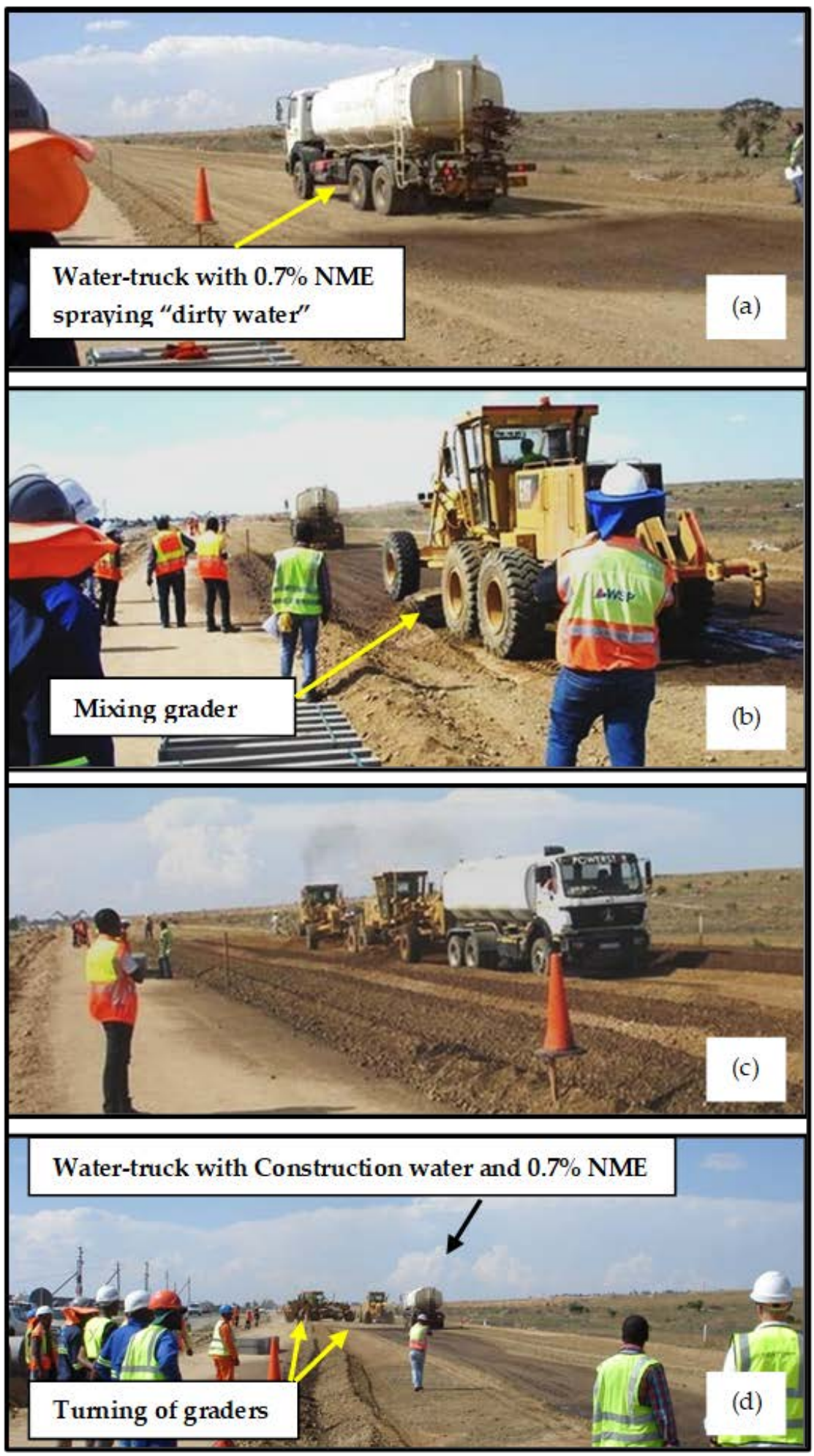

Figure 14. The granular material for the construction of the sub-base is spread along the section to be stabilised and compacted, allowing for the compaction factor. (a) The water-bowser containing the anionic NME pre-mixed with the required construction water is starting with the spraying of the NME mix. $(\mathbf{b}, \mathbf{c})$ The water-bowser is closely followed by graders that are mixing the NME stabilising agent with the construction water over the pre-determined length and width of the road. (d) Due to the turning movements and continued process of spraying and mixing, the construction of a section of road using conventional equipment is considerably more time consuming compared to the use of central mixing plants with paving equipment or with recycling equipment. 


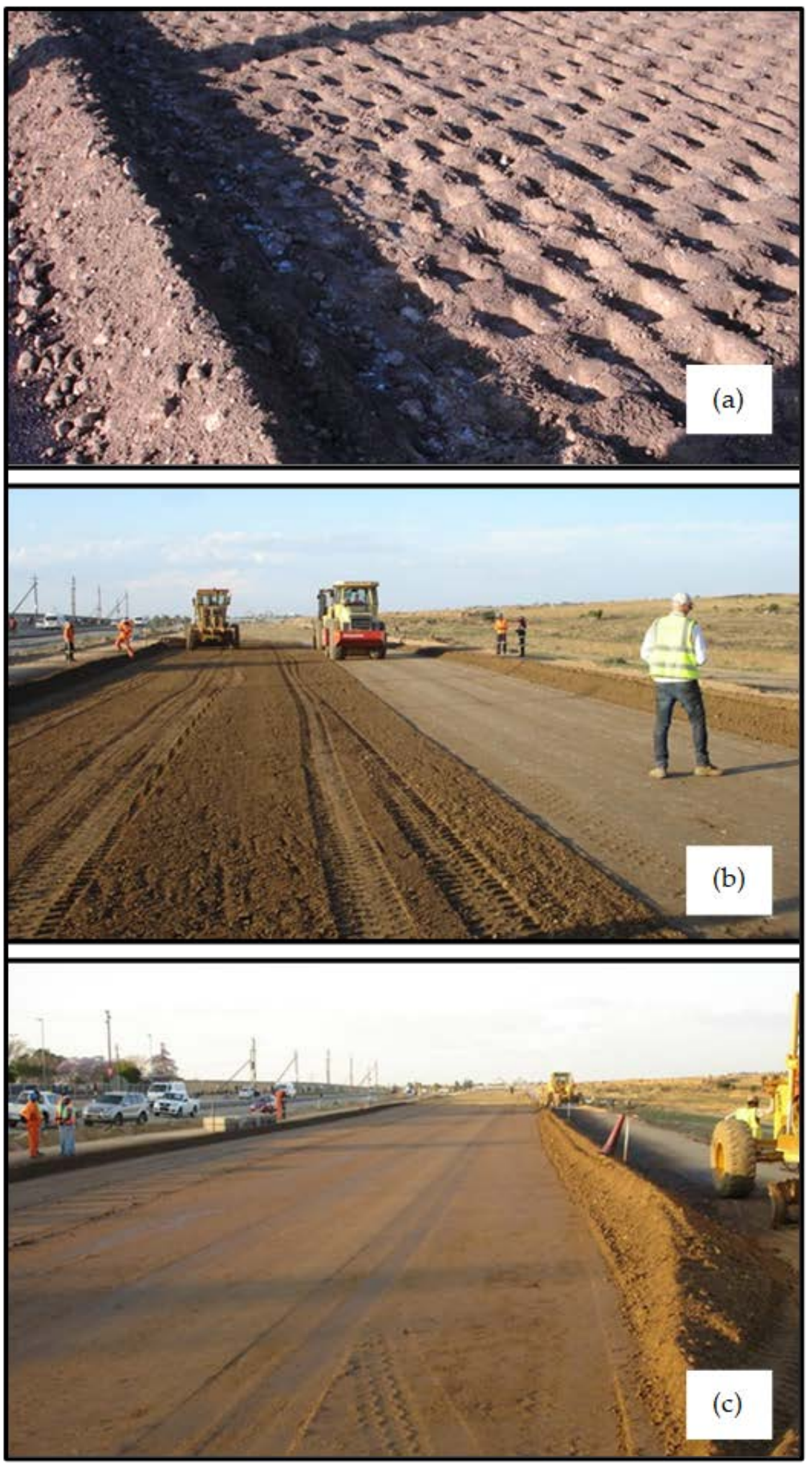

Figure 15. Compaction of the layer with the anionic NME mixed into the layer using conventional equipment; (a) using a sheep-feet roller; (b) followed by a vibratory steel-drum roller and a pneumatic roller to create a smooth surfacing; and (c) a small percentage of the NME mix is retained in the tanker as an enrichment of the top of the layer before final compaction (note that, similar to normal emulsion stabilisation, clean water should not be sprayed onto the layer). 
The following aspects is of importance to note when using conventional equipment for the NME stabilisation of granular materials:

- Material of a quality not previously considered for use in the base and sub-base-layers as a function of the required bearing capacity can successfully be stabilised meeting all the engineering requirements in terms of density and the specified UCS (dry and wet) and ITS (dry and wet) $[5,15,17,18,20]$. The compaction of a $400 \mathrm{~m}$ section of a G1 [21] layer to the required density will easily require a continuous process of compaction lasting 2 full days. Comparatively, it is not unusual to construct a $1 \mathrm{~km}$ length of a pavement layer, $10 \mathrm{~m}$ wide, to the specified density using a material-compatible NME stabilising agent, where the stabilising agent acts as a lubricant assisting in the orientation of the material that is being stabilised and compacted;

- Compaction effort is considerably less than that required for the construction of an equivalent granular layer (the modified stabilising agent acts as a lubricant, resulting in the orientation of the granular layers into firm, stabilised layers with ease);

- The general perception among construction practitioners is that it is impossible to achieve a uniform mix using emulsion percentages as low as 0.7 percent in the construction of a $150 \mathrm{~mm}$ thick pavement layer, which is not applicable when using an NME stabilising agent. The modification effectively adds a second emulsifying agent to the production process, leading to a reduction of the bitumen particles within the emulsion, resulting in a mix that is easily dispersed within the construction water and will effectively result in a uniformly stabilised layer; and

- No curing of an NME-stabilised layer is required, considerably reducing the risk associated with cement-treated layers.

A cut through and across the sub-base-layer of the dual carriageway constructed with 0.7 percent (about 0.4 percent residual bitumen) of a G5/6-quality material using conventional construction equipment is shown in Figure 16. The evenly distributed NME stabilising agent is clearly seen as indicated. This layer is the same sub-base constructed as shown in Figures 14 and 15.

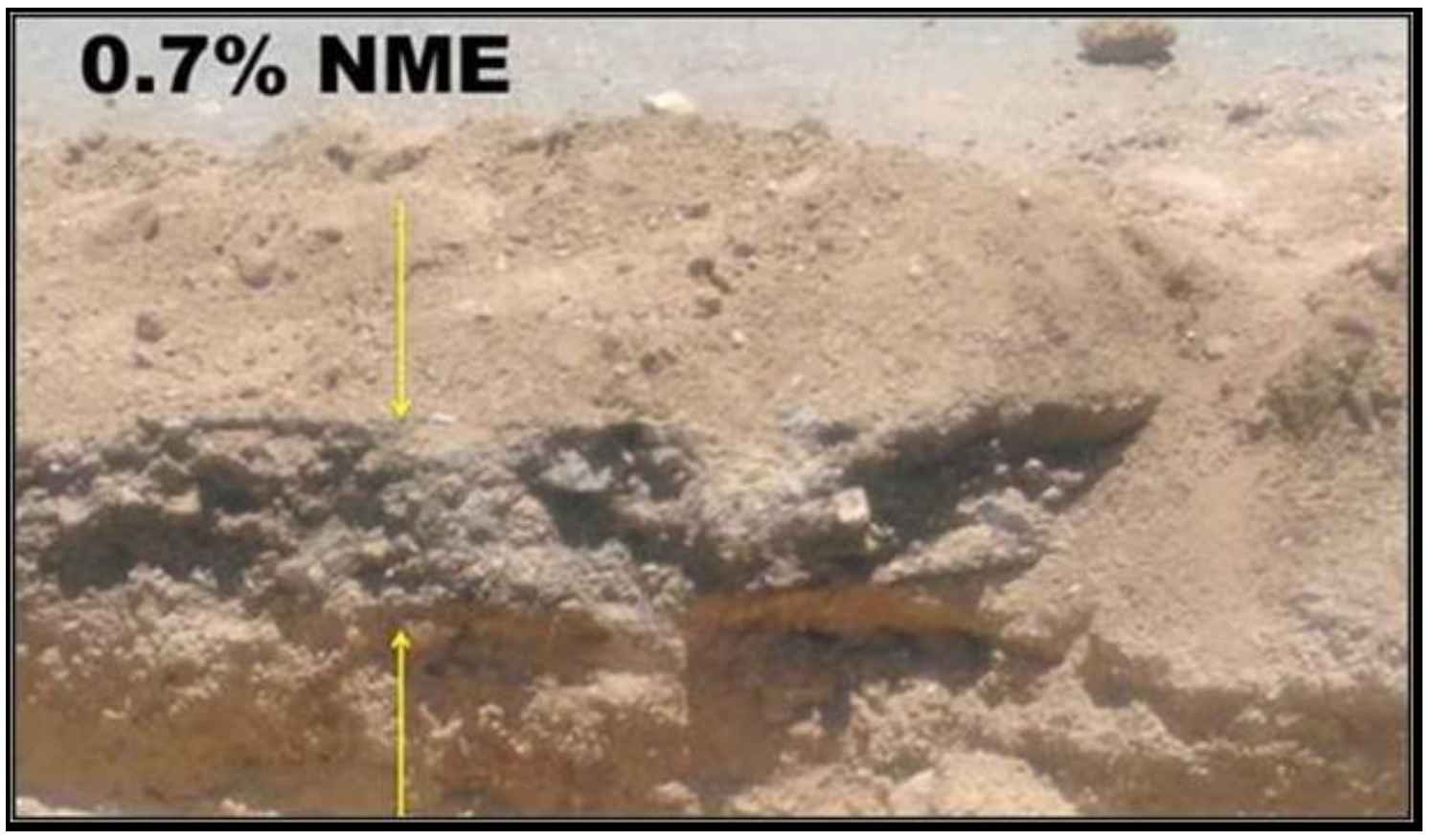

Figure 16. Cut through the stabilised sub-base constructed using a water-cart for distribution of the $0.7 \%$ anionic NME stabilising agent added to the construction water and mixed by grader, compacted as shown in Figures 14 and 15. 


\subsubsection{Construction and Upgrading of a Secondary Rural Road}

The construction process for all categories of roads using conventional equipment is similar in nature as described under the previous sections. In this example, material was also imported on a compacted in situ prepared roadbed. Material of a G7-quality (refer to Figure 1) was used to construct a single $150 \mathrm{~mm}$ thick layer on top of the prepared baselayer. Only one grader was used in the mixing of the material. The construction process and condition 6 years after completion of this secondary road are shown in Figure 17.

6.4.4. Construction and Upgrading of a Local Access to Farms and Villages/Townships Using In-Situ Materials

The depth to which the in-situ materials need to be stabilised is determined during the structural design process for the different material sections identified along the length of the road as per the detailed design method [6,27]. Independent of the requirements and decisions with regard to the level of the labour-intensive construction to be implemented, the following basic steps need to be followed, as shown in Figure 19:

- The in-situ material needs to be ripped to the required depth;

- Over-sized material (usually more than $1 / 3$ of the thickness of the layer) needs to be removed. This can be done manually and the stone used for the protection of drainage facilities if required;

- The ripped material needs to be windrowed, enabling the layer below to be compacted to the minimum required Dynamic Cone Penetrometer (DCP) penetration levels required for the layer at that depth within an applicable climatic zone (Appendix $C$ and $\mathrm{D}$ in Reference [27]). This process will also ensure that the material to be stabilised is constructed to the correct thickness. DCP penetration rates per blow (DCP-DN values) as per the recommended design method [27] can be used for a quick and easy quality control for the compacted layer on which the stabilised layer is to be constructed;

- The material can either be mixed with the stabilising agent by hand and transferred back onto the compacted layer or transferred back and mixed using conventional equipment such as a grader and water-bowser with compaction equipment. Compaction for Category D and E roads [27] can be achieved using small pedestrian-type construction equipment to achieve the required densities. For Category D and $\mathrm{E}$ roads, the densities can also quickly and easily be determined using the DCP equipment to evaluate the required DCP-DN values for that specific layer [27];

- The top of the base-layer should be treated with an anionic silane-modified nanopolymer to ensure that a firm base-layer is achieved with a high-water resistance and protection against any possible damage, especially if it is to be opened to traffic before the surfacing is applied. For implementing agencies requiring a "natural" soil look to an upgraded gravel road, a second application of the anionic silanemodified nano-polymer is recommended. The anionic silane-modified nano-polymer can easily be applied by hand or sprayed by water-cart onto the finished base-layer. Suitable application rates for the treatment of the base-layer should be determined using trail sections. An application of $2 \mathrm{~L} / \mathrm{m}^{2}$ of a diluted treatment (as per supplier recommendation) is suitable for the priming of an unstabilised base-layer. Stabilised base-layers will normally require a lesser application rate; and

- A suitable surfacing can be applied using mostly hand-mixed materials such as slurries and sand seals, and for a more durable surfacing, even an NME binder Cape seal [19] using labour-intensive construction options can be used, as illustrated in Figures 18 and 20.

An example of the construction of pavement layers using an anionic NME stabilising agent for the upgrading of tertiary access roads is shown in Figure 21. The slurry application by hand can be done similarly to that shown for the Cape seal without the single seal using an NME binder to provide water-resistant, cost-effective protection to lower-order roads. 


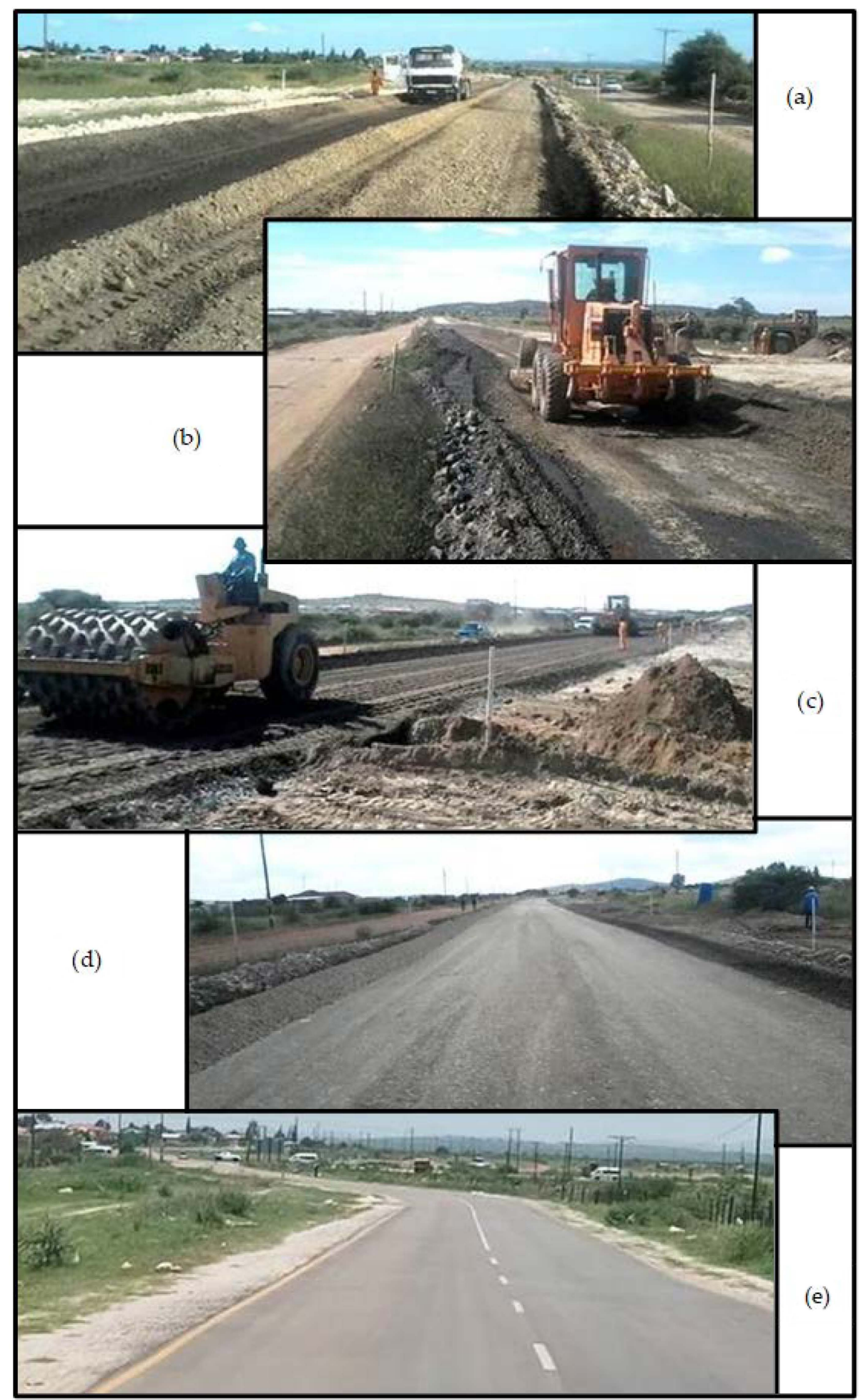

Figure 17. (a) Water-bowser with construction water and anionic NME stabilising agent. (b) Single grader used for mixing of the anionic NME stabilising agent pre-mixed within the construction water. (c) Compaction and cutting of final layer levels. (d) Condition of the compacted layer prior to applying a tack-coat and surfacing. (e) Condition of the surfaced road 6 years after completion. 


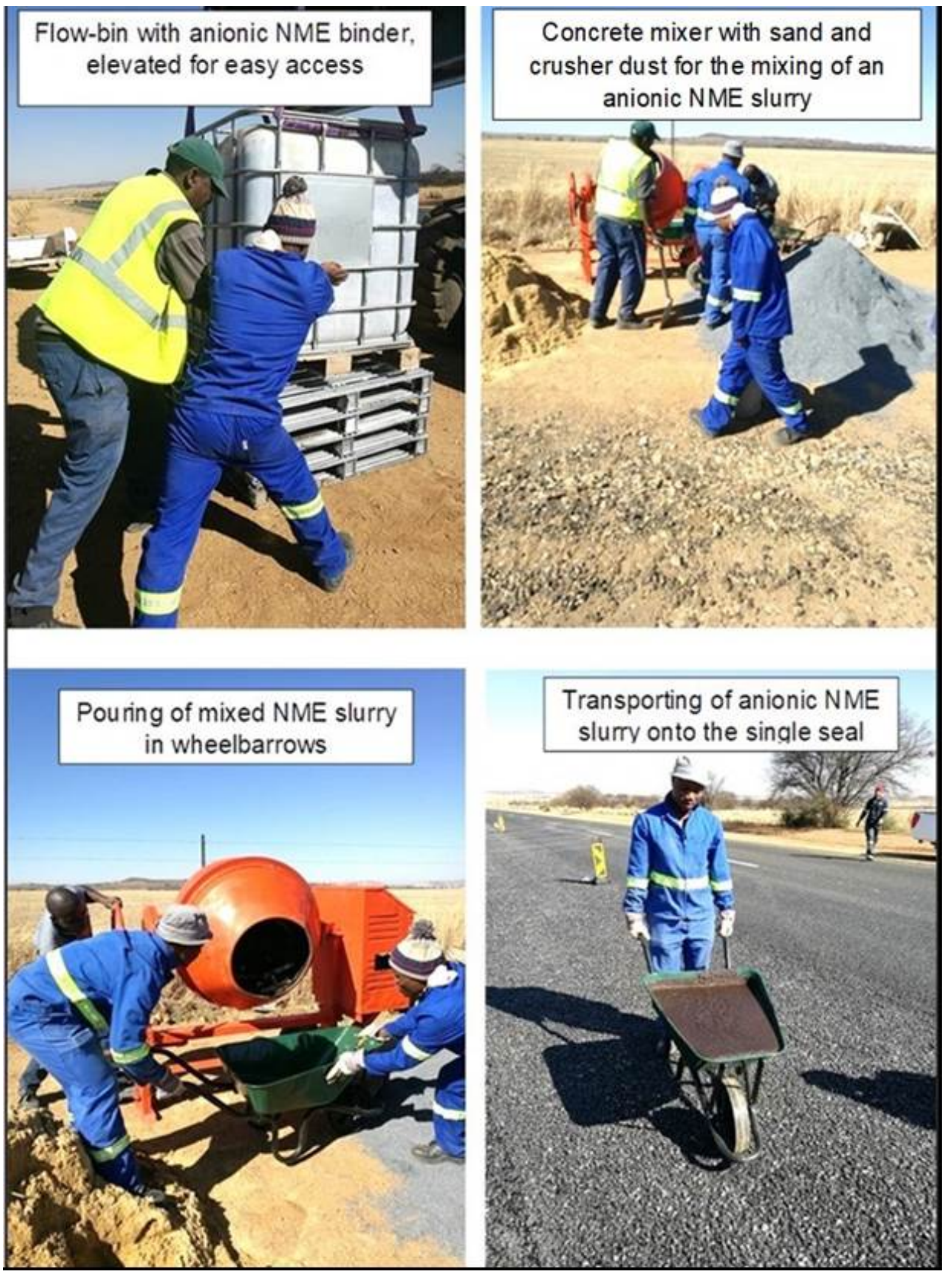

Figure 18. Labour-intensive road-side manufacturing of the slurry mix for a modified cape seal using an anionic NME binder. 


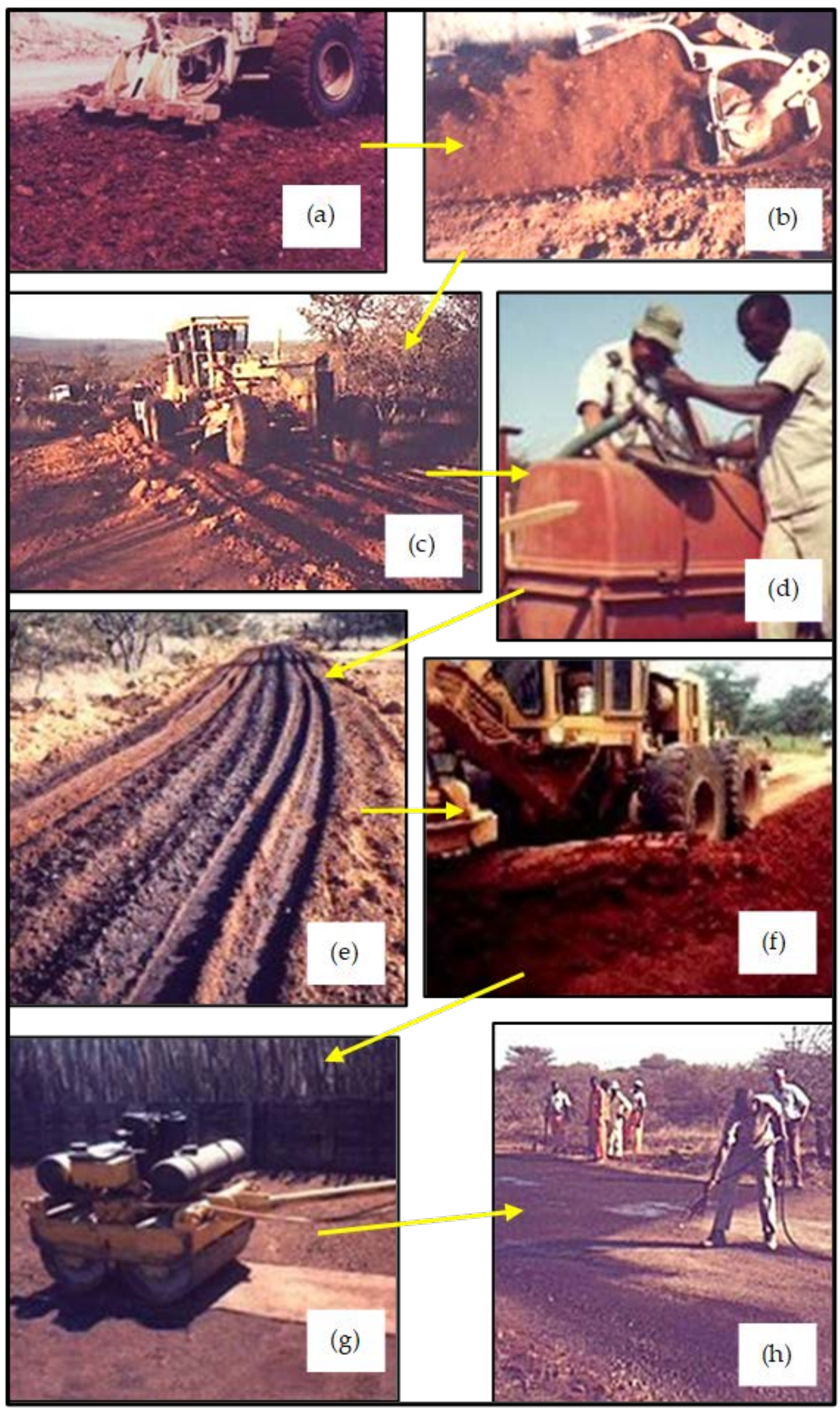

Figure 19. (a) Ripping by grader and (b) scarifying of in situ material using a rotavator to both loosen material to the required depth and expose oversized material for removal by hand. (c) Ripping of layer to create layer depth exposure for ease of application of the construction water-diluted anionic NME stabilising agent. (d) Mixing of the NME stabilising agent in a rudimentary water tanker. (e) Spraying of the diluted NME onto the exposed material for easy mixing. (f) Mixing of material and cutting to level for compaction. (g) Compaction of the NME-stabilised base material using hand compactors. (h) Applying a prime coat by hand sprayer. 


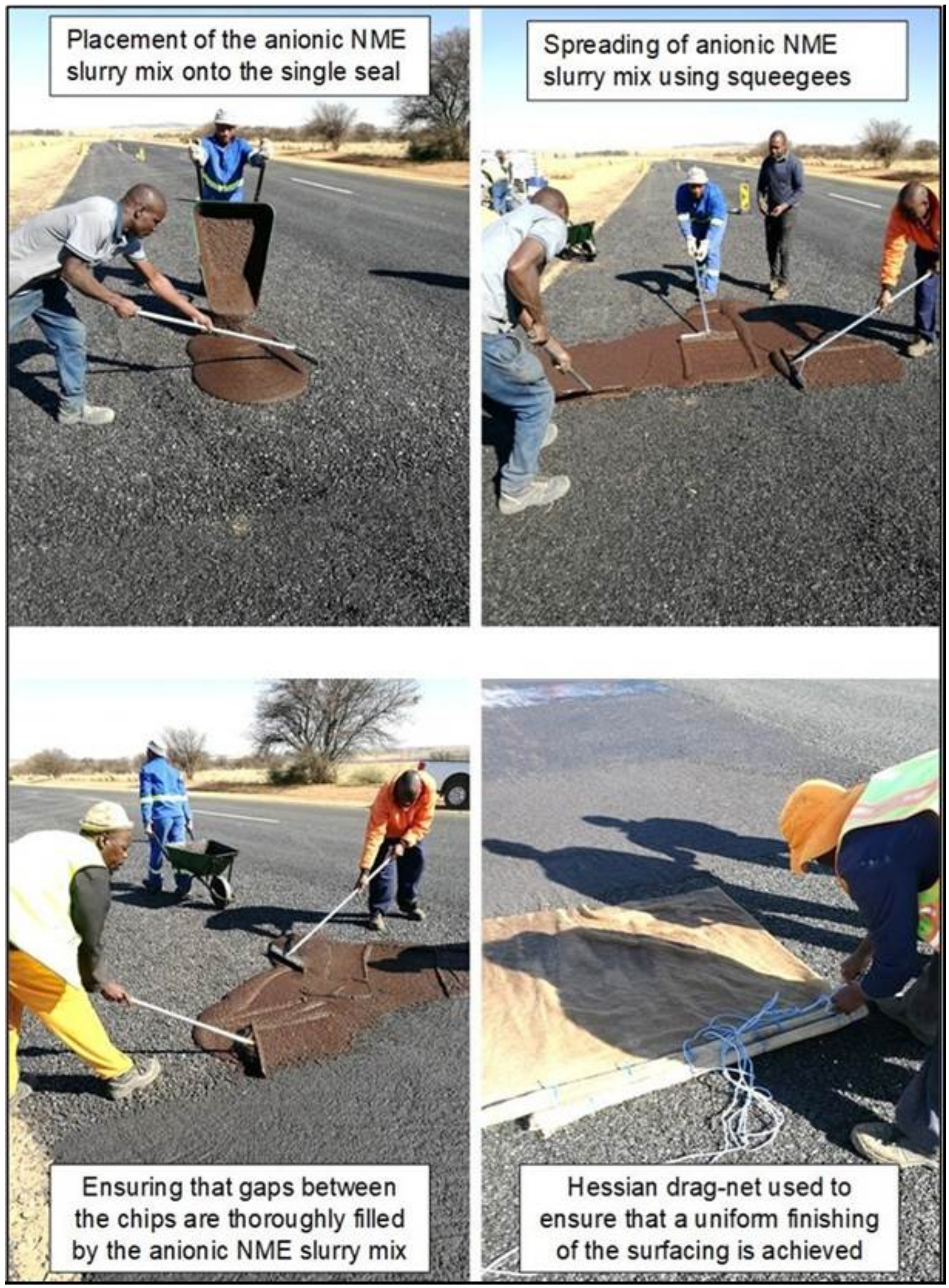

Figure 20. Labour-intensive construction of a modified cape seal using an anionic NME binder with the slurry mixed on site next to the road. 


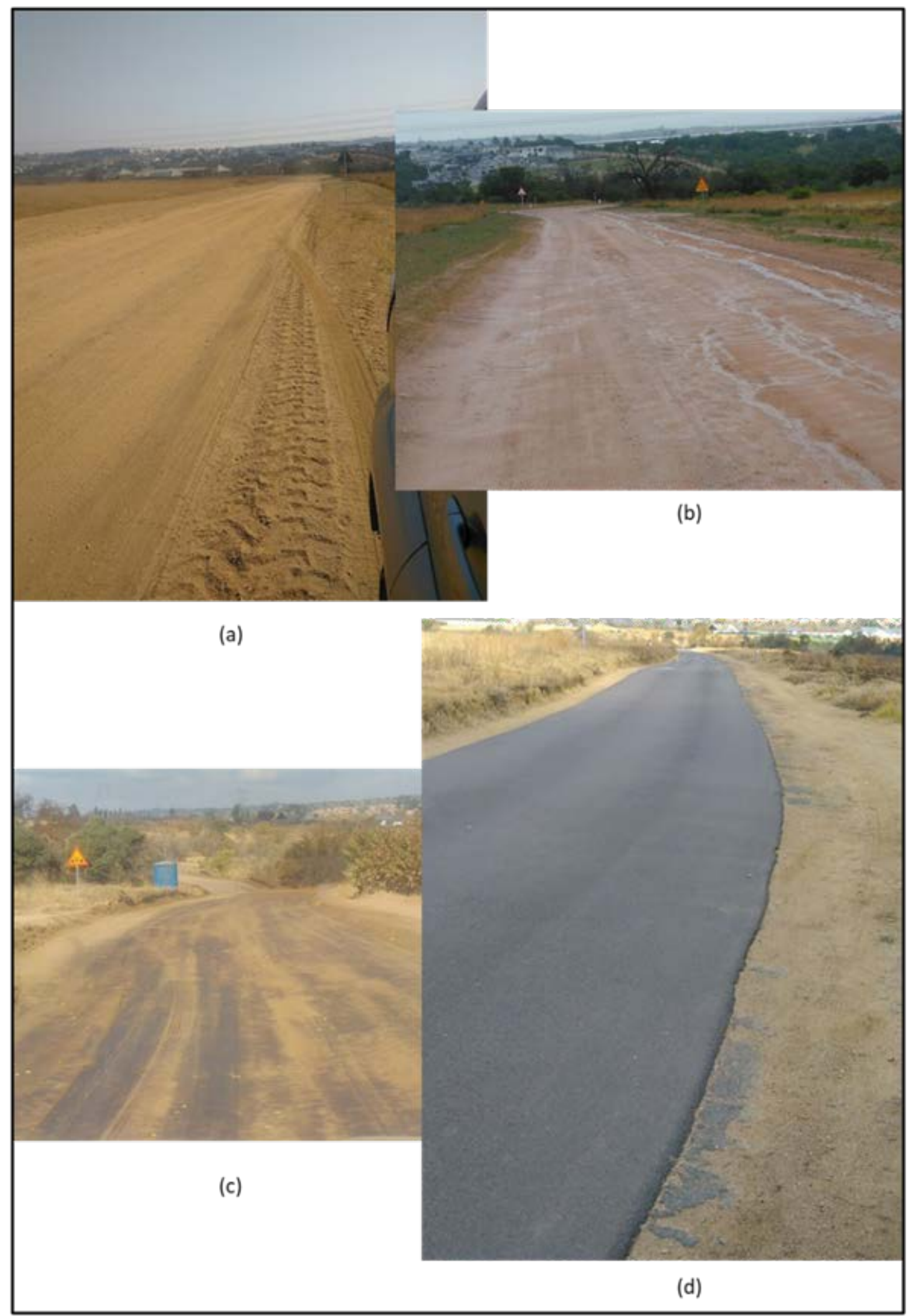

Figure 21. Upgrading of a local access road with $(\mathbf{a}, \mathbf{b})$ showing the sandy/slippery/muddy conditions prior to upgrading. (c) In total, $100 \mathrm{~mm}$ of in situ stabilisation with an anionic NME stabilising agent and (d) with an ultra-thin fine-graded asphalt surfacing (specified by client). 


\section{Conclusions}

Granular materials traditionally classified as marginal in terms of their use on various road categories, stabilised and improved by using material-compatible nanotechnologies in the form of New-age (Nano) Modified Emulsions (NME), have been tested and evaluated over a number of years in laboratories and in practice using Accelerated Pavement Tests (ATP). Scientifically based material design methods based on the mineralogy of granular materials have been developed to ensure that potential risks associated with the introduction of new technologies are minimised, if not eliminated. From all the evidence produced, there is little doubt that the introduction of the anionic NME nanotechnology products can considerably reduce the unit costs of the provision and construction of road infrastructure.

However, the acceptance and roll-out of new technologies in the provision of bulk infrastructure need to be accepted by the construction industry. Examples have already been experienced with contractors trying to exploit the concept of "new technologies" as the basis for claims to conceal poor workmanship, equipment-related problems, or just a lack of adequate construction management. For this reason alone, it is important to document the use of NME stabilising agents in practice used in combination with the most advanced to the very basic conventional road construction equipment. It is also shown that the introduction of NME stabilising agents lends itself to projects with increased levels of labour-intensive construction methods ideally suited for use in developing areas of the world faced with high levels of unemployment.

Any new technology introduced into the construction industry must be shown to be reliable, used at an acceptable risk without considerable advanced capital investments in new equipment, and resilient in the face of unforeseen problems. No construction site is without problems and the introduction of new technologies can often be used as an "obvious" reason for failures, especially if any uncertainties exist as to the behaviour characteristics of these new technologies in practice during construction. The examples discussed in this article aim to counteract such possibilities through the demonstration of the ease of use of anionic NME stabilising agents, highlighting several advantages over the use of traditionally used stabilising agents. Actual projects covered using granular materials previously considered as of unacceptable quality include roads varying from highways to the upgrade of local access roads and the in-situ rehabilitation of urban streets. Some of these advantages include the:

- Effective use of granular materials previously considered to be of unacceptable quality;

- Enabling of the use of small percentages of residual bitumen (e.g., 0.4 per cent) to effectively stabilise granular pavement layers using conventional equipment, meeting all engineering specifications in terms of UCS and ITS, and retaining strengths (hydrophobicity) with no extra effort at application rates generally deemed by road construction practitioners to be "impossible" to achieve uniform mixes in pavement layers of a thickness of $150 \mathrm{~mm}$;

- Achieving of compaction densities using considerably less effort and energy with associated cost savings;

- Achieving of high-quality base surface finishings, meeting riding quality specifications with ease as surfacings are suitable for the placement of durable thin surfacings, such as chip seals or, even better, anionic NME-modified binder cape seals, with increased resistance to water penetration and related problems, and hence improved durability;

- Proven resilient water-repellent characteristics that have not been previously experienced with any other unprotected granular-based material;

- Construction using NME-stabilised materials results in cleaner equipment with less problems associated with blockages due to the smaller particle sizes of the binder and the fact that the binder has been modified to adhere to granular materials; even personnel will experience less problems with binders' contamination (sticking to skin) provided that the equipment is clean at the start of construction with no residue from previous projects that modifying agents can react to; 
- Stabilisation of the granular materials using a high-quality anionic NME agent can be done at ambient temperatures requiring no heating with less potential safety risks to personnel; and

- Utilisation of high-quality approved anionic NME stabilising agents, approved according to fundamental requirements as previously identified and referred to, will exclude any possibility of toxicity and negative environmental impacts through a fundamental process of product evaluation and approval in terms of chemical analytical scrutiny as a result of the scientific basis on which the anionic NME technology is based on.

In summary, the NME stabilisation of granular materials for the construction of roads is shown to be:

- Construction-friendly;

- Equipment-tolerant;

- Cost-effective;

- Environmentally friendly; and

- Non-toxic and safe to construction personnel.

Author Contributions: G.J.J., under the directive of the Head of the Department of Civil Engineering, W.J.vdM.S., have been leading the research into the provision of affordable road infrastructure at the faculty of Engineering, University of Pretoria. He has been instrumental in the design, implementation, and construction supervision of roads using nanotechnologies. W.J.vdM.S. recognised the potential of nanotechnology solutions in the field of pavement engineering more than a decade ago. G.J.J., through involvement in the private sector, has been responsible for the development of scientific principles, ensuring that implementation can be achieved at a minimum risk. All authors have read and agreed to the published version of the manuscript.

Funding: This research study received no external funding.

Institutional Review Board Statement: Not applicable.

Informed Consent Statement: Not applicable.

Acknowledgments: The support of GeoNANO Technologies (Pty) Ltd., 18 Davies road, Wychwood, Germiston, 1401, South Africa, Tel.: +27-844078489, www.geonano.co.za (Accessed on 21 December 2021), info@geonano.co.za, in support of students in the Department of Civil Engineering, University of Pretoria, Pretoria, South Africa, to test a wide variety of materials as part of final year projects and post-graduate theses testing the various principles identified in this paper is acknowledged.

Conflicts of Interest: The authors declare no conflict of interest.

\section{References}

1. Steyn, W.J.vdM. The Upside of Disruptive 4IR Technology and Innovation. University World News-Africa Edition. Available online: https:/ /www.universityworldnews.com/ (accessed on 19 April 2021).

2. Southern Africa Transport and Communications Commission (SATCC). Guideline: Low-Volume Sealed Roads; The Southern Africa Development Community (SADC), SADC House: Gaborone, Botswana, 2003; ISBN 99912-0-456-5.

3. Jordaan, G.J.; Kilian, A.; Du Plessis, L.; Murphy, M. The Development of Cost-Effective Pavement Design Approaches Using Mineralogy Tests with New Nano-Technology Modifications of Materials. In Proceedings of the 2017 Southern Africa Transportation Conference (SATC 2017), Pretoria, South Africa, 10-13 July 2017.

4. Jordaan, G.J.; Kilian, A. The cost-effective upgrading, preservation and rehabilitation of roads-Optimising the use of available technologies. In Proceedings of the 2016 Southern Africa Transportation Conference (SATC 2016), Pretoria, South Africa, 4-7 July 2016.

5. Jordaan, G.J.; Steyn, W.J.vdM. Testing of granular/soil characteristics for the optimisation of pavement designs using reactive stabilising agents including "new-age" nano-technologies. In Proceedings of the 12th Conference of Asphalt Pavements for Southern Africa (CAPSA 2019), Sun City, South Africa, 13-16 October 2019.

6. Jordaan, G.J.; Steyn, W.J.vdM. Nanotechnology Incorporation into Road Pavement Design Based on Scientific Principles of Materials Chemistry and Engineering Physics Using New-Age (Nano) Modified Emulsion (NME) Stabilisation/Enhancement of Granular Materials. Appl. Sci. 2021, 11, 8525. [CrossRef]

7. Jordaan, G.J.; Steyn, W.J.vdM. A Comprehensive Guide to the Use of Applicable and Proven Nano-Technologies in the Field of Road Pavement Engineering Design and Construction; Department of Civil Engineering, University of Pretoria: Pretoria, South Africa, 2019; ISBN 978-0-620-83022-5. 
8. SANS 3001-GR53; Civil Engineering Test Methods: Determination of the Unconfined Compressive Strength of Compacted and Cured Specimens of Cementitiously Stabilised. SABS Standards Division: Pretoria, South Africa, 2010.

9. SANS 3001-GR54; Civil Engineering Test Methods-GR54: Determination of the Indirect Tensile Strength of Compacted and Cured Specimens of Cementitiously Stabilised Materials. SABS Standards Division: Pretoria, South Africa, 2010.

10. Von Hoffman, W.J. Stone-preserving processes: Royal Institute of British Architects. Builder 1861, 19, $103-105$.

11. Wheeler, G. Alkoxysilanes and the Consolidation of Stone; The Getty Conservation Institute: Los Angeles, CA, USA, 2005.

12. Jordaan, G.J.; Steyn, W.J.vdM. Engineering Properties of New-Age (Nano) Modified Emulsion (NME) Stabilised Naturally Available Granular Road Pavement Materials Explained Using Basic Chemistry. Appl. Sci. 2021, 11, 9699. [CrossRef]

13. Jordaan, G.J.; Steyn, W.J.vdM. Fundamental principles ensuring successful implementation of new-age (nano) modified emulsions (NME) for the stabilisation of naturally available materials in pavement engineering. Appl. Sci. 2021, 11, 1745. [CrossRef]

14. National Centre for Asphalt Technology (NCAT). Effects of Nanotac Additive on Bond Strength and Moisture Resistance of Tach Coats; NCAT: Auburn, AL, USA, 2011.

15. Akhalwaya, I.; Rust, C.F. Laboratory evaluation of road construction materials enhanced with nano-modified emulsions (NME). In Proceedings of the Southern African Transportation Conference (SATC'18), Pretoria, South Africa, 9-12 July 2018.

16. Kidgell, M.M.; Steyn, W.J.vdM.; Jordaan, G.J. Effect of Nano-Modified Emulsions (NME) (nano-silanes) stabilisers on the properties of Dolomite. In Proceedings of the 2019 Southern African Transportation Conference (SATC'19), Pretoria, South Africa, 8-11 July 2019.

17. Rust, F.C.; Akhalwaya, I.; Jordaan, G.J.; Du Plessis, L. Evaluation of a nano-silane-modified emulsion stabilised base and subbase under HVS traffic. In Proceedings of the 12th Conference on Asphalt Pavements for Southern Africa (CAPSA 2019), Sun City, South Africa, 13-16 October 2019.

18. Rust, F.C.; Smit, M.A.; Akhalwaya, I.; Jordaan, G.J.; Du Plessis, L. Evaluation of two nano-silane-modified emulsion stabilised pavements using accelerated pavement testing. Int. J. Pavement Eng. 2020. [CrossRef]

19. Jordaan, G.J.; Steyn, W.J.vdM.; Broekman, A. Evaluation of cost-effective modified binder thin chip and cape seal surfacings on an anionic nano-modified emulsion (NME)-stabilised base layer using accelerated pavement testing (APT). Appl. Sci. 2021, 11, 2514. [CrossRef]

20. Jordaan, G.J.; Kilian, A.; Machiavelli, N.; Dlamini, D. Practical Application of Nano-Technology in Roads in Southern Africa. In Proceedings of the 8th Transportation Technology Transfer (T2) Conference, Lusaka, Zambia, 4-8 March 2017.

21. Committee of Land Transport Officials (COLTO). Draft TRH14: Guidelines for Road Construction Materials; National Institute for Transport and Road Research (NITRR), CSIR: Pretoria, South Africa, 1985.

22. Committee of Land Transport Officials (COLTO). Draft TRH4: Structural Design of Flexible Pavements for Interurban and Rural Roads; National Institute for Transport and Road Research (NITRR), CSIR: Pretoria, South Africa, 1996.

23. The South African Institute of Civil Engineers. General Conditions of Contract for Construction Works, 3rd ed.; The South African Institute of Civil Engineers: Midrand, South Africa, 2015.

24. American Association of State and Highway Transportation Officials (AASHTO). M145-91: Standard Specification for Classification of Soils and Soil-Aggregate Mixtures for Highway Construction Purposes; AASHTO: Washington, DC, USA, 1995.

25. American Society for Testing Materials (ASTM). D3282-09: Standard Practice for Classification of Soils and Soil-Aggregate Mixtures for Highway Construction Purposes; ASTM: Pennsylvania, PA, USA, 2009.

26. Jordaan, G.J. Optimisation of Flexible Road Pavement Rehabilitation Investigations and Design; Department of Civil Engineering, University of Pretoria: Pretoria, South Africa, 2013; ISBN 978-1-77592-036-6.

27. Jordaan, G.J.; Steyn, W.J.vdM. Cost-Effective Upgrading of Gravel Roads Using Naturally Available Materials with New-Age Modified Emulsion (NME) Stabilisation; Department of Civil Engineering, University of Pretoria: Pretoria, South Africa, 2020; ISBN 978-0-620-91415-4.

28. Rust, F.C.; Mahoney, J.P.; Sorenson, J. An International View of Pavement Engineering. In Proceedings of the 1998 Meeting of the Bearing Capacity of Roads and Airfields Conference, Trondheim, Norway, 6-8 July 1998.

29. Jordaan, G.J. Life-cycle cost analysis-An integral part of pavement rehabilitation design. In Proceedings of the 10th Conference on Asphalt Pavements for Southern Africa (CAPSA 2011), Drakensberg, South Africa, 11-14 September 2011. 